\title{
Last minute policies and the incumbency advantage*
}

\author{
Elena Manzoni ${ }^{\dagger}$ \\ Stefan P. Penczynski ${ }^{\ddagger}$
}

This paper models a purely informational mechanism behind the incumbency advantage. In a two-period electoral campaign with two policy issues, an incumbent and a possibly more competent challenger compete for election by voters who are heterogeneously informed about the state of the world. Due to the asymmetries in government responsibility between candidates, the incumbent's statement may convey information on the relevance of the issues to voters. In equilibrium, the incumbent sometimes strategically releases his statement early and thus signals the importance of his signature issue to the voters. We find that, since the incumbent's positioning on the issue reveals private information which the challenger can use in later statements, the incumbent's incentives to distort the campaign are decreasing in his quality, as previously documented by the empirical literature. The distortions arising in equilibrium are decreasing in the incumbent's true competence; however, the distortions may be increasing in the incumbent's expected competence on his signature issue.

Keywords: Incumbency advantage, electoral competition, information revelation, agenda setting.

JEL Classification: D72, D82, D60

${ }^{*}$ We thank Madhav Aney, Leonardo Felli, Giovanna Iannantuoni, Gilat Levy, Andrea Mattozzi, Michele Piccione, Ronny Razin and participants of the $3^{\text {rd }}$ GRASS Workshop, the $5^{\text {th }}$ CESIfo Workshop on Political Economy and the SFB 884 Workshop on the Political Economy of Reforms in Mannheim. We also thank the editor and three anonymous referees for their constructive comments. Elena Manzoni gratefully acknowledges financial support from PRIN (2012-2015) "New approaches to political economics: positive theories, empirical evidence and experiments in the laboratory".

${ }^{\dagger}$ Dipartimento di Economia, Metodi Quantitativi e Strategie d'Impresa, Università degli Studi di Milano-Bicocca, piazza dell'Ateneo Nuovo 1, 20126 Milano, Italy. E-mail: elena.manzoni@unimib.it

¥University of Mannheim, Department of Economics, L7 3-5, 68131 Mannheim, Germany. E-mail: stefan.penczynski@uni-mannheim.de 


\section{Introduction}

Our paper links the empirically established phenomenon of incumbency advantage to the timing of the political announcements in an electoral campaign. In our model, an incumbent, when competing against a challenger candidate for reelection, can credibly signal the relevance of an issue to the voters. This is due to government responsibilities that force him to act on problems of particularly urgent nature that we call emergencies. He can use this ability also to make salient those issues on which he is particularly competent. The flipside of this government responsibility is that an important issue might require immediate political action and force him to position himself. In response to the incumbent's action, the challenger can subsequently position himself optimally. This trade-off between influencing the agenda and revealing information governs the analysis of campaign statements in this paper.

An example of such informational manipulations can be seen in the US election campaign 2004 when incumbent George W. Bush raised the terror alert level one day after the Democratic convention, possibly undoing the traditional postconvention rise in the polls (CBS, 2004). In the remainder, we will illustrate our model with a detailed analogy to the case of Germany's chancellor Schröder who suddenly opposed the Iraq invasion in the federal election campaign 2002.

We model this trade-off in an electoral campaign over two periods with two political issues. The campaign is run by two politicians, a challenger and an incumbent. The challenger can only make statements about his proposed policies in the second period, while the incumbent can choose to take a stand on one issue in the first period. As a consequence, we can interpret period 1 as the last period of the previous government, and period 2 as the proper electoral campaign.

We assume that the incumbent is more competent on one of the two issues his signature issue - in the sense that he holds more precise information on that 
issue. The issue on which he is more competent is common knowledge; however, we assume that the extent of his competence - the precision of his information - is the incumbent's private information. The incumbent may have an incentive to focus the voters' attention on his signature issue by announcing his policy in period 1. This strategy is effective since it shifts the voters' perception of which issue is "relevant" and therefore may shift the perception of the best candidate. The incumbent's power to change the voters' beliefs on the relevance of the issues results from the existence of "emergencies" in which he is forced to take a stand on the relevant issue. The incumbent's actions in period 1 may thus be informative about the nature of the relevant issue.

The incumbent's incentive to take an early stand and influence the debate is however mitigated by the above mentioned trade-off: early announcements disclose the incumbent's private information not only to the voters, but also to the challenger, who can best respond to it. Therefore, in equilibrium it is not always optimal for an excellent incumbent to reveal his precise information and influence the electorate's political agenda. In other words, the returns to incumbency are decreasing in the quality of the incumbent. This is in line with the findings of the empirical literature; Aidt, Veiga and Veiga (2011) show how the incumbent's opportunistic behavior that distorts the electoral campaign diminishes when the incumbent's win-margin increases. Gordon and Landa (2009) provide a number of models in which high quality incumbents benefit less from the incumbency advantage, with the best incumbents potentially suffering from incumbency.

Our model shows that the decreasing incentive of a high quality incumbent to distort the electoral campaign does not translate in a monotonically more efficient outcome. In particular we find that welfare is influenced both by the incumbent's competence and by the beliefs on such competence. While an incumbent with a higher competence always improves the chances of appropriate policy measures, 
the challenger mimics the incumbent only when he believes that his information is good enough. A mimicking challenger, however, is not providing the voters with alternatives, therefore an incumbent with a better reputation does not necessarily result in better options. The inefficiencies that arise from the incumbent's and the challenger's behavior therefore respond differently to the expected and the true competence. First of all they are decreasing in the incumbent's true expertise. Their response to the incumbent's reputation for competence instead varies: if the incumbent's true expertise is low an increase in his reputation will increase the inefficiencies; if his true expertise is high an increase in his reputation will decrease them. There is therefore an interesting interaction between the incumbent's characteristics and his reputation in the determination of welfare.

In our model, the incumbent's power of shifting voters' beliefs originates from the existence of emergencies on the relevant issue. We can interpret these emergencies in a twofold way. First of all, they may be serious emergencies, which induce the incumbent government to declare a properly defined state of emergency. The declaration of a state of emergency can be made strategically, as discussed by Bjørnskov and Voigt (2016), who argue that emergency laws can be misused to remain in office. Alternatively, we can have a milder type of emergency, which induces the incumbent government to promptly deal with specific issues by either implementing a policy or taking a public position; this is the interpretation of our leading example on the 2002 federal election campaign in Germany. Our model can explain the strategic uses of both types of emergencies in order to improve the position of the incumbent government.

Our model is related to two different branches of the literature. The main one is the wide literature on the incumbency advantage. The common explanations for such an advantage can be grouped in three categories: (i) Environmental characteristics of the campaign make the campaigning process easier for the in- 
cumbent. ${ }^{1}$ (ii) Incumbent's characteristics that differ from the challenger's ones through the selection process of the previous election. ${ }^{2}$ (iii) The incumbent's position provides opportunities he uses in his favor. ${ }^{3}$

The rationale that we provide for the existence of an incumbency advantage falls in the latter category. The incumbent is able to actively distort the electoral campaign in order to increase his chances of being elected. The models that are closest in spirit to ours are by Hodler, Loertscher and Rohner (2010), Dellis (2009) and Glazer and Lohmann (1999). The first paper considers the pre-election implementation of inefficient policies that later increase the pressure to act on the incumbent's signature issues. In this paper, the authors find that intermediate types of the incumbent have incentives to distort the campaign. Our model differs from theirs in the channel through which distortions to the electoral campaign are induced. In particular, Hodler, Loertscher and Rohner (2010) show that the incumbent may implement inefficient policies in order to generate his incumbency advantage; we show that this distortion is possible even with an incumbent who only implements what he believes to be the most appropriate policy on every issue, so that it is really the information that distorts beliefs and voter's behavior. Moreover, we find distortions induced directly by both the incumbent's action and the challenger's best response. As a consequence we are able to separate the effects of the incumbent's competence from the effects of the beliefs of such competence.

Dellis (2009) and Glazer and Lohmann (1999) analyze how the treatment of some issues can influence which other issues will be salient in the next election.

\footnotetext{
${ }^{1}$ See, for example, Prior (2006) who assumes a greater media coverage for the incumbent and Gordon, Huber and Landa (2007) who investigate the effects of entry costs for the challenger.

${ }^{2}$ See, for example, Ashworth and de Mesquita (2008) who model how a quality-based incumbency advantage endogenously arises through electoral selection and strategic challenger entry.

${ }^{3}$ Examples are an increased constituency service (Fiorina, 1977) or redistricting (Cox and Katz, 2002).
} 
Dellis (2009) analyzes this phenomenon when policy makers are constrained to implement only one policy per period, while Glazer and Lohmann (1999) consider an electoral competition in which the incumbent government can have policy commitment before the election. Both papers are framed in a setup that is structurally different from ours as they deal with ideological candidates that can make issues salient by avoiding to implement a policy on them; we take an opposite view on this, as the incumbent in our model can increase the saliency of one issue only by taking an early stand on it, and by doing so he is forced to disclose his information to the challenger who can best respond to it. A complementary analysis of the use of information in the incumbent-challenger race is provided by Ashworth and Shotts (2011), who analyze the effects of the strategic choice of a challenger who can provide soft or hard information on the incumbent's policy choice to the voter. In their model, an incumbent advantage arises when the challenger is silent, as part of the optimal incentive scheme that induces the challenger to gather costly information.

A second related branch of the literature considers agenda setting and the timing of statements. Petrocik (1996) introduces the view that the competence of a politician in a particular field ("issue ownership") is relevant for his success. Abbe, Goodliffe, Herrnson and Patterson (2003) model how politicians' success depends on whether their core competencies are "high on the agenda". Our setup is inspired by these concepts; we model the agenda setting process by issues' true relevance for the voters and the competency of the candidates by the precision of their information. In this literature, the most relevant paper for our work is Egorov (2015) which takes a complementary approach: in a world where voters care about multiple issues he analyzes the behavior of candidates who are constrained to campaign only on one of those issues.

Section 2 introduces the general features of the model. The analysis of the 
equilibria is contained in Section 3. Section 4 presents an analysis of the distortions that the incumbency advantage may induce. Section 5 concludes after a brief discussion.

\section{The model}

We consider a two-period model in which an incumbent $I$ and a challenger $C$ compete to be elected by a voter after a two-period electoral campaign on issues $a$ and $b$. The optimal policy on each issue $j=a, b$ is equal to the state of the world on that issue, $\omega_{j} \in\{-1,1\}$, where both states are equally likely. The state of the world on each issue is unknown during the campaign, and voters and candidates are heterogeneously informed about $\omega_{j}$.

Notice that we assume that the optimal policy is objectively known to be equal to the state of the world for every agent (candidates and voter); that is, we do not assume heterogeneity in preferences.

\subsection{Voter}

At the beginning of period 1, a representative voter receives two private signals $v_{j}, j=a, b$, about issue $j$ 's state of the world, where $v_{j}=\omega_{j}$ with probability $\delta>\frac{1}{2}$; signals are independent across issues. The precision of the signal $\delta$ is common knowledge.

The voter's utility is affected only by the policy implemented on one of the issues, which we call the "relevant" issue. The identity of the relevant issue is ex-ante unknown; the voter's belief is that $a$ is the relevant issue with probability $r ; r$ is the voter's private information.

Given his signals, the voter follows a simple behavioral rule. At the time of the election he votes for the candidate who proposes the best policy on the issue that he views more likely to be relevant. ${ }^{4}$ If both candidates propose the same

\footnotetext{
${ }^{4}$ We are aware that this is a strong assumption in a model with two issues, but we believe
} 
policy on that issue the voter randomizes with equal probability between the two candidates. The voter casts his vote comparing candidates only on a small set of issues and does not use less relevant issues as a tie-breaker. ${ }^{5}$ Moreover, we assume that the voter follows his own signal whenever it is in contrast with other sources of information characterized by the same precision. That is to say, whenever indifferent the voter follows his own information.

Both candidates' belief on $r$ is described by a uniform distribution over the interval $[0, k]$ with $\frac{1}{2}<k \leq 1$. Therefore the candidates and the voter believe $a$ is more likely to be relevant with $\operatorname{Pr}\left(r \geq \frac{1}{2}\right)=\frac{2 k-1}{2 k} \leq \frac{1}{2}$; this implies that the two issues are asymmetric from an ex-ante perspective.

\subsection{Candidates}

The two candidates maximize the probability of being elected by taking one of two positions $p_{j}^{I}, p_{j}^{C} \in\{-1,1\}$ on each issue. They are not characterized by ideological preferences.

Candidates are asymmetric in three ways. First, at the beginning of period 1 each candidate receives signals on the state of the world with different precisions. The incumbent's signal on issue $j$ is $s_{j} \in\{-1,1\}$ and the challenger's is $t_{j} \in$ $\{-1,1\}$. C's signal $t_{j}$ is correct with probability $\delta_{j}=\delta \in\left(\frac{1}{2}, 1\right)$ for both issues, reflecting that he is equally competent on both issues. ${ }^{6}$ The incumbent is instead more competent on issue $a$ than on issue $b$. More precisely, I's signal on $b$ is

that it is a useful representation of electoral processes with many independent issues. Under such conditions boundedly rational voters may be induced to consider only the set of issues that they believe will be more relevant for the next period. This is in line with psychological evidence such as in Herstein (1981).

${ }^{5}$ We interpret ties as being broken by looking at idiosyncratic, random differences between candidates that are not explicitly modelled here. This interpretation of the tie-breaking rule is close in spirit to the introduction of a valence parameter, such as, for example, in Laslier (2006).

${ }^{6}$ The challenger's signals have the same precision as the voter's signals. This is mostly for notational ease; the results do not change substantially if we assume that the precision of the voter's signals differs from the precision of the challenger's ones, provided that the voter is weakly more informed than the challenger. Recall that $\delta$ is common knowledge. 
uninformative, $\gamma_{b}=\frac{1}{2}$, and $\gamma_{a}>\frac{1}{2}$. Consequently, the incumbent can have an objectively worse $\left(\gamma_{a}<\delta\right)$ or better $\left(\gamma_{a}>\delta\right)$ signal than the challenger on issue $a .^{7}$ We assume $\gamma_{a}$ to be a random variable, distributed according to a continuous probability distribution function $f$ with support $\left[\frac{1}{2}, 1\right]$ and expected value $\mathbb{E}\left(\gamma_{a}\right)<\frac{\delta^{2}}{1-2 \delta+2 \delta^{2}}$; the cumulative distribution function is denoted $F$. The precise value of $\gamma_{a}$ is the incumbent's private information. The upper bound on its expected value is such that a voter who receives opposing signals from the incumbent and the challenger will find it optimal to follow his own signal. Notice that it is commonly known that $\gamma_{b}=\frac{1}{2}$; therefore it is common knowledge that the incumbent is never more competent on $b$ than on $a .^{8}$

Second, while both candidates can make statements in the second period, which we consider as the proper election campaign, only the incumbent can take a stand on one issue in the first period. This can be viewed as the last government period, in which he can propose or implement a policy on one of the issues. This is without loss of generality. The challenger has indeed no extra information on the issues' relevance that can induce the voter to update his beliefs. Therefore an early announcement by the challenger would simply reveal his strategic position to the incumbent, without changing the probability that the election focuses on a specific issue. Every politician can take a stand on each issue only once because he effectively commits to the proposed policies.

Finally, with probability $z$ there is an "emergency" on the relevant issue, which can be observed only by the incumbent. In this case, it is the incumbent govern-

\footnotetext{
${ }^{7}$ The model can easily be extended to the case of a challenger that is not equally competent on both issues. This delivers no further insights as most of the strategic behavior comes from the incumbent. The case of an equally competent incumbent, instead, is not relevant for our analysis, as it displays no incentive at all for the incumbent to influence the voters' perception of the issues.

${ }^{8} \mathrm{~A}$ similar information setting could arise if the candidates get differently precise signals about the voters preferences with respect to policies which arise probabilistically from the state of the world. To accomodate this interpretation of the model, the precision of the voter's signal should be set to $\delta=1$.
} 
ment's responsibility to act immediately on such issue. This puts a restriction on the incumbent's set of feasible strategies such that he has to act on the relevant issue by announcing $p_{j}^{I}$ in period 1. Emergencies can arise only on relevant issues. Due to his position, the incumbent gets to know whether there is an emergency on either issue through his signal $\zeta \in\{a, b, \emptyset\} .^{9}$

Politicians cannot hide an emergency from the public, while they can make believe that there is an emergency even when this is not the case.

The challenger's strategy is a mapping

$$
\sigma^{C}:\{-1,1\}^{2} \times\{\emptyset,-1,1\}^{2} \rightarrow\{-1,1\}^{2}
$$

associating a pair of promises $\left(p_{a}^{C}, p_{b}^{C}\right)$ to the vector that includes the signals $\left(t_{a}, t_{b}\right)$ and the incumbent's observed promise (if any).

The incumbent's action space is instead $\{A, B, \emptyset\} \times\{-1,1\}^{2}$, where $A$ and $B$ indicate the choice of promising $p_{a}^{I}$ or $p_{b}^{I}$, respectively, in the first period, and $\emptyset$ the waiting until the second period. With the signals on the states of the world and the emergency, the incumbent's strategy is

$$
\sigma^{I}:\{a, b, \emptyset\} \times\{-1,1\}^{2} \rightarrow\{A, B, \emptyset\} \times\{-1,1\}^{2}
$$

where the following restrictions from emergency apply:

$$
\begin{aligned}
& \sigma^{I}\left(a, s_{a}, s_{b}\right) \in\{A\} \times\{-1,1\}^{2}, \\
& \sigma^{I}\left(b, s_{a}, s_{b}\right) \in\{B\} \times\{-1,1\}^{2} .
\end{aligned}
$$

No restriction applies to $\sigma^{I}\left(\emptyset, s_{a}, s_{b}\right)$.

\subsection{Timing}

Figure 1 summarizes the timing of the electoral campaign. At the beginning of the first period, the voter, the incumbent, and the challenger receive signals

\footnotetext{
${ }^{9}$ We interpret this sharp constraint implied by the emergency as follows. If the incumbent remains inactive, the existence of an emergency will be observed by the voters, and the incumbent will not be elected in the subsequent election as a punishment for the absence of timely measures.
} 
$\left(r, v_{a}, v_{b}\right),\left(\zeta, s_{a}, s_{b}\right)$ and $\left(t_{a}, t_{b}\right)$, respectively. In the first period, the incumbent decides whether to promise $p_{a}^{I}, p_{b}^{I}$, or nothing, where his choice is constrained in the case of an emergency on the relevant issue. All other promises are revealed in the second period, the electoral campaign period. In period 3 , the voter casts his vote.

\begin{tabular}{|c|c|c|c|c|c|}
\hline \multicolumn{3}{|c|}{ Information } & & \multicolumn{2}{|c|}{ Actions } \\
\hline $\begin{array}{c}\text { Voter } \\
\left(r, v_{a}, v_{b}\right)\end{array}$ & $\begin{array}{l}\text { Incumbent } \\
\left(\zeta, s_{a}, s_{b} ; \gamma_{a}\right)\end{array}$ & $\begin{array}{c}\text { Challenger } \\
\left(t_{a}, t_{b}\right)\end{array}$ & $i^{t}=1$ & Incumbent & 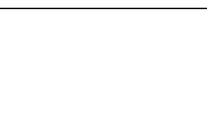 \\
\hline & & & $t=2$ & $\prod_{\left(p_{a}^{I}, p_{b}^{I}\right)}^{\text {Incumbent }}$ & $\begin{array}{c}\text { Challenger } \\
\left.\qquad p_{a}^{C}, p_{b}^{C}\right)\end{array}$ \\
\hline & & & $\iota_{t}=3$ & Voter & \\
\hline
\end{tabular}

Figure 1: Timing of the electoral campaign.

\subsection{Updated relevance}

The voter updates the belief $r$ according to the incumbent's behavior. The updating is induced by the possibility of an emergency on the relevant issue, in which case observing a promise on issue $j$ in the first period is informative about its relevance.

Consider issue $a$. Let $y$ be the probability that $a$ is spoken about in equilibrium when there is no emergency. With probability $z$ there is an emergency on the relevant issue and the incumbent is forced to position himself on the relevant issue. The voter's posterior belief when he observes a first period announcement 
on $a$ becomes via Bayes' rule ${ }^{10}$

$$
\rho=\frac{(z+y(1-z)) r}{(z+y(1-z)) r+(1-r)(1-z) y} .
$$

If $\rho$ is greater than $\frac{1}{2}$ the voter bases his decision on issue $a$, which occurs when $r>\frac{(1-z) y}{2 y-(2 y-1) z}$.

\subsection{An exemplary case}

The German general election on 22 September 2002 presents a fitting illustration of the modelled mechanism. The incumbent Chancellor Gerhard Schröder $(I)$ led a coalition of Social Democrats and Greens, which, at the end of July 2002, was "trailing the conservative opposition $(C)$ by a substantial margin" in the opinion polls. (Fürtig, 2007, pp. 315)

Ten months after the attacks of 11 September 2001, the issue of fighting terrorism (issue $a$ ) only occupied the sixth rank of important political problems. 85 percent of the population saw unemployment and the state of the economy as the main issue (issue $b$ ) in the country.

The conservative parties in Germany are traditionally closer to business and the supply side of the economy than the Social Democrats. They are perceived as more competent on matters of the economy. Conversely, any pacifistic attitudes of the German electorate are better reflected in the more left incumbent coalition which could therefore gain from a rejection of a military intervention against Saddam Hussein.

Indeed, in response to worsening public opinion polls, Schröder's party "decided on 1 August to begin the final phase of the re-election campaign earlier

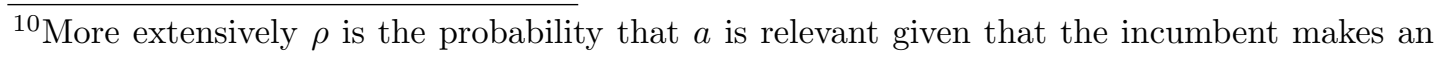
announcement on $a$ in period 1 . Such announcement can be due to (i) an emergency on the relevant issue $a$, which happens with probability $z r$; in this case the probability of an announcement on $a$ is 1, (ii) $a$ being relevant but no emergency, which happens with probability $r(1-z)$; in this case the probability of an announcement on $a$ is $y$, (iii) $b$ being relevant but no emergency, which happens with probability $(1-r)(1-z)$; also in this case the probability of an announcement on $a$ is $y$. The only case in which there can be no early announcement on $a$ is when $b$ is an emergency (probability $(1-r)(1-z)$ ).
} 
than planned." (Fürtig, 2007, p. 315). That day he stated: "We have alarming news from the Middle East. There is talk of a war. [...] Germany is willing to show solidarity, but is not available for adventures." (Ddp News Agency quoted in Fürtig, 2007, p. 316). Schröder thus used information that his government position brought in order to strongly impact the perceived relevance of the topic of war and terrorism.

If the US had suddenly invaded Iraq on 1 August 2002, an emergency would have pressed the German chancellor to take a stand on this issue. On the other hand, the alleged upcoming invasion could be used by the incumbent to claim an emergency and position himself on the matter, independently of whether it ever happened.

Within one month of the above statement, the perceived importance of the Iraq conflict jumped from 6th to 2 nd rank although it was very uncertain that a war would ever be fought and German support ever requested from the US. The elections on 22 September saw the incumbent coalition confirmed. (Fürtig, 2007, pp. 317)

\section{Equilibrium analysis}

We now proceed to the analysis of the equilibrium behavior of the agents in this electoral system. Given the voter's behavioral voting rule (Section 2.1), and his belief updating according to Bayes' rule (Section 2.4), a Perfect Bayesian Equilibrium of the campaigning game is given by a pair of strategies $\left(\sigma^{I}, \sigma^{C}\right)$ such that (i) $I$ maximizes his expected utility for each profile of signals $\left(\zeta, s_{a}, s_{b}\right)$, (ii) $C$ maximizes his conditional expected utility upon observing $i$ 's first period promise (if any) for each profile of signals $\left(t_{a}, t_{b}\right)$, and (iii) beliefs are updated by Bayes' rule, if possible.

The first aspect to be considered is what happens in the simplest case, in 
which all the political action is concentrated in the second period. In this period the candidates' announcement has no effect on the voter's belief about which issue is relevant; therefore, announcements released in this stage cannot move the voter's attention from one issue to the other one. Hence, in this stage, candidates choose on each issue the promise that is more likely to correspond to the voter's belief about the true state of the world. Notice that the voter receives informative signals on both issues, and that he is as informed as the challenger. As a consequence, the game does not display uninformative equilibria in which both candidates announce the same constant policy, given that the voter would optimally follow his signal after a challenger's deviation, and hence the challenger would profitably deviate to a truthful announcement. Moreover, our assumption that the voter randomizes between candidates whenever they propose the same policy, allows us to exclude polarized equilibria (in which each candidate propose a different constant policy), and equilibria in which only one candidate follows his signal. Hence, the second stage equilibrium behavior is uniquely the truthful revelation of candidates' signals. In this respect we differ from Laslier and Van der Straeten (2004) who showed that more equilibria arise when both candidates are more informed than the voter. More precisely, the challenger makes announcements according to his signals on both issues, and the incumbent does the same on issue $a$; any announcement on issue $b$ is an equilibrium announcement for the incumbent, as his signal on $b$ is uninformative.

The more interesting aspects of the model are related to the incumbent's choice of timing of his announcements, and to the challenger's second period behavior when the incumbent announces his policy promise in the first period.

To understand the incumbent's behavior we first notice that, given the informational structure of this model, an early announcement beyond emergency on issue $j$ increases the perceived relevance of issue $j$. Therefore the incumbent 
makes a first period promise on issue $b$ only when he is forced to, i.e. when there is an emergency on $b$. As for issue $a$, it can be shown that also in the first period it is optimal for the incumbent to promise what he believes to be the true state of the world, that is, $p_{a}^{I}=s_{a}$. If he is in an equilibrium in which the challenger mimics him, the incumbent is indifferent between any promise in the first period; if however in equilibrium the challenger follows his own signal (at least with positive probability), it is strictly better for the incumbent to promise the policy that corresponds to his signal, otherwise his winning probability is lowered. The incumbent's timing, instead, depends both on the precision of his signal $s_{a}$ and on the challenger's behavior. By announcing his policy promise $p_{a}^{I}$ in the first period, the incumbent reveals his information to the challenger. If the challenger never mimics the incumbent upon observing $p_{a}^{I}$, every type of incumbent optimally promises $p_{a}^{I}$ in the first period; in this way the incumbent increases the likelihood that $a$ is the decisive issue for the election, without changing the challenger's behavior, that is, without altering the conditions of the competition. If there is a positive probability that the challenger will mimic the incumbent's promises, instead, only incumbents with a low $\gamma_{a}$ will make an early announcement on $a$; a first period promise on $a$ in this case has two effects: it increases the likelihood that $a$ will be the decisive issue, but it also reduces the incumbent's probability of winning the competition on issue $a$. As the cost of such early intervention on $a$ is increasing in $\gamma_{a}$, while the benefit is constant, the incumbent's strategy is characterized by a threshold $\Xi$ below which the incumbent promises $p_{a}^{I}$ in the first period.

The challenger's behavior, instead, can depend only on the distribution of $\gamma_{a}$, not on $\gamma_{a}$ itself. Given the incumbent's threshold strategy, if the distribution $f$ gives sufficient weight to low competencies $\left(\mathbb{E}\left(\gamma_{a}\right)<\delta\right)$, the challenger never mimics the incumbent; this implies that all types of incumbents are active in 
the first period. If $f$ gives sufficient weight to high competencies, so that the incumbent's expected precision conditional on the fact that he announces $p_{a}^{I}$ in the first period is greater than the challenger's precision on $a$ the challenger always mimics the incumbent. In this case the challenger finds the incumbent's signal more reliable in expectation than his own, even conditioning on the fact that the incumbent's type is low enough to speak in the first period. ${ }^{11}$ Intermediate cases generate challenger's mixed behavior. Proposition 1 fully characterizes the equilibrium behavior and the relevant thresholds, depending on the perceived level of competence of the incumbent. The formal proof is included in the Appendix.

Proposition 1 The unique Perfect Bayesian Equilibrium is characterized as follows, depending on the properties of $F(\cdot)$.

(Region 1) $\mathbb{E}\left(\boldsymbol{\gamma}_{\mathbf{a}}\right)<\boldsymbol{\delta}$.

- The incumbent promises $p_{j}^{I}=s_{j}, j=a, b$. If $\zeta=j$ he promises $p_{j}^{I}$ in the first period; if $\zeta=\emptyset$ he promises $p_{a}^{I}$ in the first period.

- The challenger promises $p_{b}^{C}=t_{b}$ and $p_{a}^{C}=t_{a}$.

(Region 2) $\frac{(\mathbf{1}-\mathbf{z}) \mathbf{F}(\boldsymbol{\Xi}) \mathbf{2 k}}{\mathbf{z}(\mathbf{2 k}-\mathbf{1})+(\mathbf{1}-\mathbf{z}) \mathbf{F}(\boldsymbol{\Xi}) \mathbf{2 k}} \mathbb{E}\left(\gamma_{\mathbf{a}} \mid \gamma_{\mathbf{a}} \leq \boldsymbol{\Xi}\right)+\frac{\mathbf{z}(\mathbf{2 k}-\mathbf{1})}{\mathbf{z}(\mathbf{2 k}-\mathbf{1})+(\mathbf{1}-\mathbf{z}) \mathbf{F}(\boldsymbol{\Xi}) \mathbf{2 k}} \mathbb{E}\left(\boldsymbol{\gamma}_{\mathbf{a}}\right)>\boldsymbol{\delta}$.

- The incumbent promises $p_{j}^{I}=s_{j}, j=a, b$. If $\zeta=j$ he promises $p_{j}^{I}$ in the first period; if $\zeta=\emptyset$ he promises $p_{a}^{I}$ in the first period if and only if $\gamma_{a}<\Xi$, where $\Xi=\min (1, \max (0.5, \xi))$ and $\xi$ is the solution to the implicit equation $\Xi=\delta+\frac{([2 F(\Xi)-(2 F(\Xi)-1) z]-2 F(\Xi)(1-z))\left(\frac{1}{4}-\delta+\delta^{2}\right)}{(2 k-1)\left(\delta-\frac{1}{2}\right)[2 F(\Xi)-(2 F(\Xi)-1) z]}$.

${ }^{11}$ The incumbent's expected precision given that the challenger observes an early announcement on $a$ and given that the incumbent makes early announcements in absence of an emergency only for $\gamma_{a}<\Xi$ is

$$
\frac{(1-z) F(\Xi) 2 k}{z(2 k-1)+(1-z) F(\Xi) 2 k} \mathbb{E}\left(\gamma_{a} \mid \gamma_{a} \leq \Xi\right)+\frac{z(2 k-1)}{z(2 k-1)+(1-z) F(\Xi) 2 k} \mathbb{E}\left(\gamma_{a}\right) .
$$

The updating weights the incumbent's unconditional expected type, and the expected type when $\gamma_{a}<\Xi$ for the (ex-post) probability that there is an emergency on $a$ and for the ex-post probability that there is no emergency on $a$, respectively. 
- The challenger promises $p_{b}^{C}=t_{b}$ and $p_{a}^{C}=t_{a}$ if there has been no annoucement on $a$ in the first period, and $p_{a}^{C}=p_{a}^{I}$ otherwise.

(Region 3) $\frac{(\mathbf{1}-\mathbf{z}) \mathbf{F}(\boldsymbol{\Xi}) \mathbf{2 k}}{\mathbf{z}(\mathbf{2} \mathbf{k}-\mathbf{1})+(\mathbf{1}-\mathbf{z}) \mathbf{F}(\boldsymbol{\Xi}) \mathbf{2 k}} \mathbb{E}\left(\boldsymbol{\gamma}_{\mathbf{a}} \mid \boldsymbol{\gamma}_{\mathbf{a}} \leq \boldsymbol{\Xi}\right)+\frac{\mathbf{z}(\mathbf{2 k}-\mathbf{1})}{\mathbf{z}(\mathbf{2} \mathbf{k}-\mathbf{1})+(\mathbf{1}-\mathbf{z}) \mathbf{F}(\boldsymbol{\Xi}) \mathbf{2 k}} \mathbb{E}\left(\boldsymbol{\gamma}_{\mathbf{a}}\right)<\boldsymbol{\delta}$ and $\mathbb{E}\left(\boldsymbol{\gamma}_{\mathbf{a}}\right)>\boldsymbol{\delta}$

- The incumbent promises $p_{j}^{I}=s_{j}, j=a, b$. If $\zeta=j$ he promises $p_{j}^{I}$ in the first period; if $\zeta=\emptyset$ he promises $p_{a}^{I}$ in the first period if and only if $\gamma_{a}<\Xi\left(\beta^{*}\right)$, where $\Xi\left(\beta^{*}\right)>\Xi$ is such that $\frac{(1-z) F\left(\Xi\left(\beta^{*}\right)\right) 2 k}{z(2 k-1)+(1-z) F\left(\Xi\left(\beta^{*}\right)\right) 2 k} \mathbb{E}\left(\gamma_{a} \mid \gamma_{a} \leq\right.$ $\left.\Xi\left(\beta^{*}\right)\right)+\frac{z(2 k-1)}{z(2 k-1)+(1-z) F\left(\Xi\left(\beta^{*}\right)\right) 2 k} \mathbb{E}\left(\gamma_{a}\right)=\delta$.

- The challenger promises $p_{b}^{C}=t_{b}$ and $p_{a}^{C}=t_{a}$ if there has been no announcement on a in the first period; if the incumbent has announced $p_{a}^{I}$ in the first period the challenger promises $p_{a}^{C}=p_{a}^{I}$ with probability $\beta^{*}$ and $p_{a}^{C}=t_{a}$ otherwise. The mixing probability $\beta^{*}$ is such that the incumbent is indifferent between speaking in the first and in the second period when $\gamma_{a}=\Xi\left(\beta^{*}\right)$.

The model (and Proposition 1) focuses on the case in which the challenger is equally competent on both issues, while the incumbent is more competent on issue $a$ and less competent than the challenger on issue $b$. This is the parametric region in which the timing of the election statements is most interesting. The model can however be solved for all other regions. In the following, we briefly describe what happens under the other possible conditions.

When both politicians are equally competent across issues, the incumbent's likelihood of winning is the same regardless of which issue is considered by the voters. He therefore has no incentive to distort the campaign.

If the incumbent is better informed on both issues, $\left(\gamma_{a}>\delta_{a}\right.$ and $\left.\gamma_{b}>\delta_{b}\right)$, the incumbent has even less incentives to distort the campaign. His probability of winning if voters focus on any issue $j$ is $\frac{1+\gamma_{j}-\delta_{j}}{2}>\frac{1}{2}$. Suppose now that he tries to distort the campaign in favor of issue $a$ : by doing so he reveals his signal on 
$a$, the challenger mimics him and his probability of winning on issue $a$ decreases to $\frac{1}{2}$, so that the incumbent now has a higher probability of winning on issue $b$. However, the likelihood that voters focus on issue $a$ increases, so that the incumbent is unambiguously worse off by trying to influence the debate.

In the remaining cases of both politicians or only the challenger being more competent on one issue, the intuition is the same as in our main analysis. As long as the incumbent can increase his likelihood of winning by moving the electorate's attention to a particular issue, the behavior will qualitatively be as predicted in the model. Only the parameter regions in which different equilibria arise will change.

\section{Distortions and inefficiencies}

The behavior described in Proposition 1 describes distortions on the candidates' side which decrease the probability that the policy implemented corresponds to the true state of the world on the relevant issue. The benchmark is the case in which both politicians follow their signal and the incumbent speaks in the first period only when there is an emergency. In this scenario the probability of electing a politician who implements the optimal policy is increasing in $\gamma_{a}$. This is due to the fact that a higher competence increases the probability that a candidate promising the "correct" policy is offered in the election.

We can distinguish three distortions when the incumbent can choose to speak in the first period without emergency. First, in the benchmark, the incumbent speaks in the first period only when there is an emergency, which can only be on the relevant issue; therefore the emergency of the issue reveals its relevance with certainty. Once the early statement on issue $a$ might be due to the incumbent's interest, the emergency on such an issue can not always be recognized. Hence, the voter has a distorted expectation of the relevant issue and may not vote 
optimally, as he assigns a probability smaller than 1 to an emergency on $a$ when it is relevant. Since in every equilibrium there is a positive probability that the incumbent speaks on $a$ in the first period when there is no emergency on $a$, such emergency on $a$ can never be perfectly recognized.

Second, when the incumbent makes a statement on $a$ in the absence of emergency in the first period, he influences the agenda in the sense that he distorts the perception of which issue is most likely to be relevant. The voter has a distorted expectation of the relevant issue and may not vote optimally, as he assigns a probability higher than $r$ to $a$ being the relevant issue. This distortion is present in region 1 for all incumbent's types and in regions 2 and 3 for low incumbent's types.

The third effect results from the challenger mimicking the incumbent's statement. The probability that the election offers a candidate who promises the right policy is diminished as a result of the challenger not using the information of his signal. This effect has a positive side as well: due to the mimicking, the probability that the incumbent is elected when the voters vote on issue $a$ decreases, and therefore the probability of having a candidate who implements the correct policy on $b$ increases. However, the overall effect of this distortion is negative. This type of distortion arises when the incumbent speaks in the first period without emergency and the challenger mimics the incumbent, and is therefore present only when $\mathbb{E}\left(\gamma_{a}\right)>\delta$ (i.e. for distributions of types in regions 2 and 3 ) and for low types of the incumbent (i.e, $\gamma_{a}$ smaller than the relevant threshold). Moreover, since the probability of mimicking in region 3 is $\beta<1$, this distortion has a smaller impact in region 3 than in region 2, so that the equilibrium in region 3 outperforms the one in region 2 for low types.

In our exemplary case, the three distortions would be 1) the inability to perfectly identify an emergency on an issue like the Iraq invasion from the words 
of the Schröder administration during an election campaign, 2) a biased agenda with terrorism suddenly and possibly undeservedly rivaling the importance of the economic problems and 3) the voter's reduced choice set if the challenger copies the incumbent's position, like Stoiber, the conservative candidate, initially attempted (Fürtig, 2007, p. 318).

For exemplary parameter values, figure 2 illustrates the benchmark and the three equilibria obtained under different distributions of $\gamma_{a}{ }^{12}$

It illustrates that the probability of electing a politician who proposes the correct policy is always increasing in $\gamma_{a}$ but it displays non-monotonic patterns in the expected value of $\gamma_{a}$ (Equilibria 1 - 3). For example, an increase in the expected competence of the incumbent does not necessarily imply a better outcome for the voters. More precisely, a low $\mathbb{E}\left(\gamma_{a}\right)$ (thickly dotted Eq. 1) induces a higher welfare if the true competence of the incumbent is low $\left(\gamma_{a}<0.75\right)$. Conversely, when the true competence of the incumbent is high, a high $\mathbb{E}\left(\gamma_{a}\right)$ (red dotted Eq. 2) leads to a higher probability of implementing the correct policy. The same is true for the intermediate value of $\mathbb{E}\left(\gamma_{a}\right)$ (lightly dotted Eq. 3), the effect, however, only kicks in when the incumbent refrains from early statements, which happens here for a higher $\gamma_{a}$. We can therefore conclude that a higher competence of the incumbent is beneficial for voters' welfare; however, the expected competence may be detrimental because it may trigger more distortions that affect negatively the probability of implementing the correct policy.

A more detailed and analytical analysis of the distortions that arise in the three types of equilibrium is included in the Appendix.

\footnotetext{
${ }^{12} \gamma_{a}$ is distributed according to $\operatorname{Beta}\left(\alpha_{\beta}, \beta_{\beta}\right)$ distributions with parameter $\alpha_{\beta}=1.5$ and three different parameters $\beta_{\beta} \in\{0.4,2,5\} . \mathbb{E}\left(\gamma_{a}\right) \equiv \frac{\alpha_{\beta}}{\alpha_{\beta}+\beta_{\beta}}$.
} 
Figure 2: Probability of implementing the correct policy in different equilibria. Example with $\delta=2 / 3, k=0.75, z=0.1$.

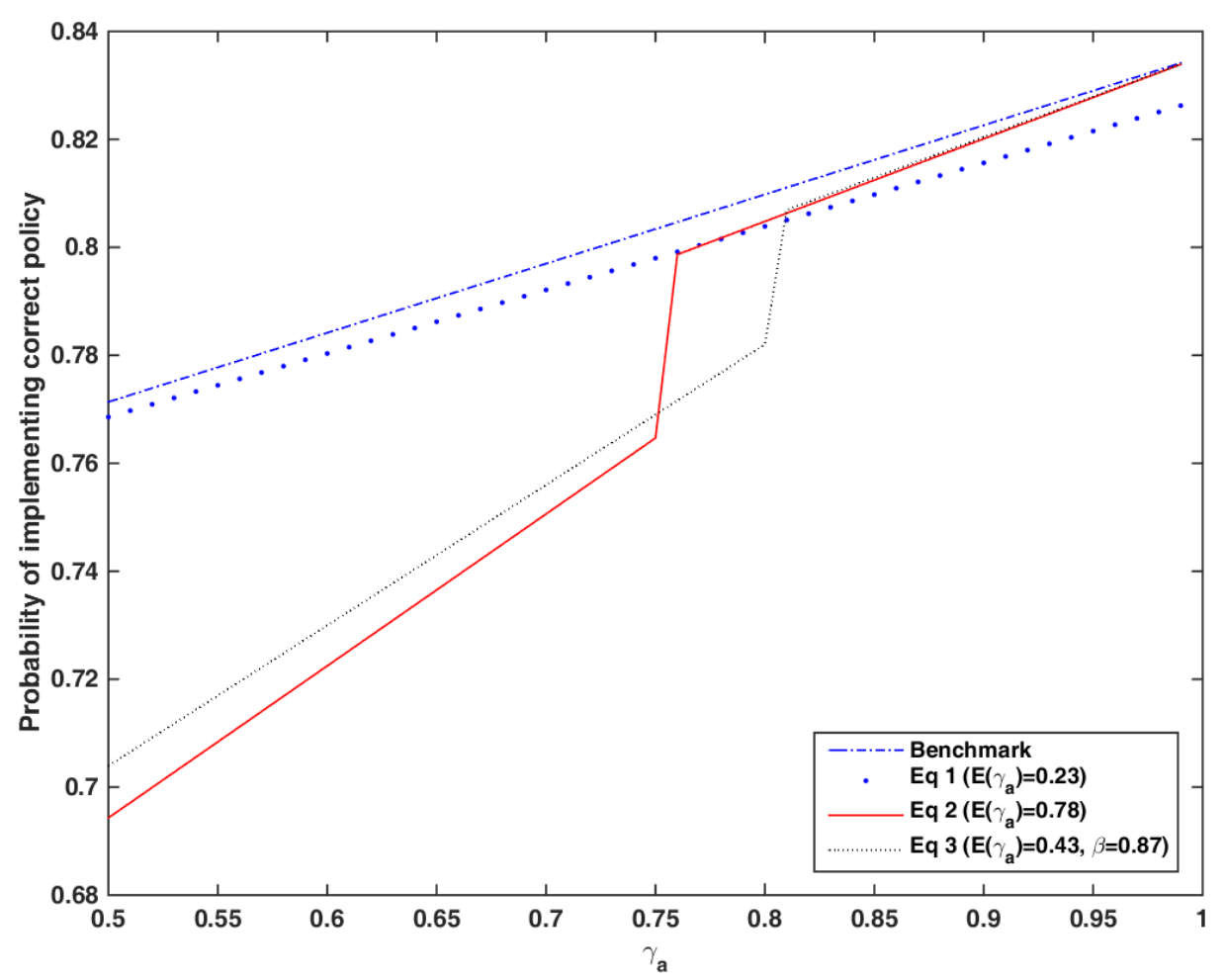

\section{Conclusion}

This paper models a purely informational mechanism behind the incumbency advantage. We analyze a two-period electoral campaign characterized by two policy issues in which an incumbent competes against a possibly more competent challenger. Due to his government responsibilities, the incumbent's statements can credibly attach importance to issues and influence the political agenda.

We illustrate the model with a close analogue from German politics, German Chancellor Gerhard Schröder's strict opposition to the Iraq War which he first revealed during the reelection campaign 2002. This example clearly shows how the incumbent administration used its government responsibility as well as its alleged 
office-related informedness to influence the political agenda in its favor. Our formal treatment investigates the fundamental mechanism behind such agenda setting and allows us to identify resulting distortions. The analysis of this novel rationale for the incumbency advantage delivers the following predictions.

First, the incumbent can have an advantage even when he is objectively worse than the challenger. This is in contrast to the hypothesis of an electoral selection process that links the incumbency advantage with superior quality of the incumbent.

Second, the incumbent does not always have incentives to influence the debate and to use his advantage. If his signal is very informative, he waits to make a statement and does not give the challenger the possibility to respond optimally to his information. Indeed, the returns to incumbency are decreasing in the quality of the incumbent. In other words, if his precise information makes re-election probable enough in itself, he chooses not to influence the agenda.

Finally, we show that even given that the incumbent's incentives to distort the campaign are decreasing in the incumbent's quality, the probability of implementing the correct policy is monotonically increasing in the degree of the incumbent's competence; however, voters' welfare behaves non-monotonically with respect to the expected degree of competence. We show that having an incumbent who is expected to be objectively worse than the challenger may be better for the electorate than one who is expected to be partially more competent only on one of the issues.

The mechanism covered in our paper can be linked to other interesting topics. Closely related is the improvement of an incumbent government's position through the declaration of a state of emergency. Bjørnskov and Voigt (2016) provide an empirical analysis of the determinants of the use of emergency laws, and suspect that some emergencies may primarily be declared to strengthen the 
incumbent's position. They suggest that the mechanism could be that the state of emergency allows the incumbent to postpone elections; this mechanism is more likely to be in place in countries with weak democratic institutions. We argue that the strategic use of emergencies to improve the incumbent's position can be at work also in strong democracies, where the channel may be the distortions of voters' perception of what is relevant for the future. 


\section{References}

Abbe, Owen G., Jay Goodliffe, Paul S. Herrnson, and Kelly D. Patterson, "Agenda Setting in Congressional Elections: The Impact of Issues and Campaigns on Voting Behavior," Political Research Quarterly, 2003, $56(4), 419$.

Aidt, Toke S., Francisco José Veiga, and Linda Gonçalves Veiga, "Election results and opportunistic policies: A new test of the rational political business cycle model," Public Choice, 2011, 148 (1), 21-44.

Ashworth, Scott and Ethan Bueno de Mesquita, "Electoral Selection, Strategic Challenger Entry, and the Incumbency Advantage," The Journal of Politics, October 2008, 70 (4), 1006-1025.

and Kenneth Shotts, "Challengers, democratic contestation, and electoral accountability," Working Paper, Stanford Graduate School of Business 2011.

Bjørnskov, Christian and Stefan Voigt, "Why Do Governments Call a State of Emergency," Mimeo 2016.

CBS, "No Convention Bounce For Kerry," Newspaper article, 2 August 2004. http://www.cbsnews.com/news/no-convention-bounce-for-kerry/.

Cox, Gary W. and Johnathan Neil Katz, Elbridge Gerry's Salamander, Cambridge University Press, 2002.

Dellis, Arnaud, "The Salient Issue of Issue Salience," Journal of Public Economic Theory, 2009, 11 (2), 203-231.

Egorov, Georgy, "Single-Issue Campaigns and Multidimensional Politics," Working Paper 21265, National Bureau of Economic Research June 2015.

Fiorina, Morris P., "The Case of the Vanishing Marginals: The Bureaucracy Did It," The American Political Science Review, 1977, 71 (1), pp. 177-181. 
Fürtig, Henner, "Playing the muscle-man or new self-assuredness?

Germany and the Iraq War," International Journal of Contemporary Iraqi Studies, 2007, 1 (3), 311-329.

Glazer, Amihai and Susanne Lohmann, "Setting the Agenda: Electoral Competition, Commitment of Policy and Issue Salience," Public Choice, 1999, $99(3 / 4), 377-394$.

Gordon, Sanford C. and Dimitri Landa, "Do the Advantages of Incumbency Advantage Incumbents?," The Journal of Politics, 2009, 71 (04), $1481-1498$.

_ , Gregory A. Huber, and Dimitri Landa, "Challenger entry and voter learning," American Political Science Review, 2007, 101 (02), 303-320.

Herstein, John A., "Keeping the voter's limits in mind: A cognitive process analysis of decision making in voting.," Journal of Personality and Social Psychology, 1981, 40 (5), 843.

Hodler, Roland, Simon Loertscher, and Dominic Rohner, "Inefficient policies and incumbency advantage," Journal of Public Economics, 2010, 94 (9-10), $761-767$.

Laslier, Jean-François, "Spatial approval voting," Political Analysis, 2006, $14(2), 160-185$.

and Karine Van der Straeten, "Electoral competition under imperfect information," Economic Theory, 2004, 24 (2), 419-446.

Petrocik, John R., "Issue Ownership in Presidential Elections, with a 1980 Case Study," American Journal of Political Science, 1996, 40 (3), 825-50. Prior, Markus, "The Incumbent in the Living Room: The Rise of Television and the Incumbency Advantage in U.S. House Elections," The Journal of Politics, 2006, 68 (3), pp. 657-673. 


\section{A. Proof of Proposition 1}

We prove Proposition 1 by a sequence of claims. Remember that the voter focuses only on the issue that he believes to be more likely to be relevant. We begin our analysis with the behavior of candidates in the second period, when nothing has been announced in the first period. Hence, we can focus on the optimal behavior on every single issue separately, as in the last stage there is no interaction between issues. Our setup therefore reminds of the model of Laslier and Van der Straeten (2004), with three important differences. First, it is not the case that all candidates are more competent than the voter. Notably, the challenger's precision is equal to the voter's one. Moreover, we assume that the voter breaks ties by randomizing between candidates with equal probability, and favours his own signal whenever it has the same precision as the endogenous information received by the candidates. These three differences allow us to conclude that the best that candidates can do is to match the policy offer with the state. More precisely, if the voter's precision is weakly larger than the challenger's one we can prove that Type 1 equilibria of Laslier and Van der Straeten (2004) are not equilibria in our model. Secondly, the assumption on the voter's randomization when candidates propose the same policy allows us to rule out Type 2 and Type 3 equilibria of Laslier and Van der Straeten (2004). This implies that the challenger promises $p_{j}=t_{j}$ for every issue $j$ and that the incumbent promises $p_{a}=s_{a}$; the incumbent's promise on issue $b$ is undetermined, as his signal on $b$ is uninformative.

The incumbent's possible 4 pure strategies on each issue are $p_{j}^{I}=1, p_{j}^{I}=-1$, $p_{j}^{I}=s_{j}$ and $p_{j}^{I}=-s_{j}$. The same holds for the challenger. We prove that truthful equilibrium exists in the second period (Claim 2). Then, we show that it is unique by ruling out equilibria in which both candidates play a constant strategy (Claim 3 and 4), those in which they play opposite to the signal (Claim 5) and those in which only one of the candidates plays according to his signal (Claim 6). 
Claim 2 If nothing has been announced in the first period on issue $j$, the following is an equilibrium: $p_{j}^{I}=s_{j}, p_{j}^{C}=t_{j}$, and the voter votes according to his signal whenever the two proposals differ.

\section{Proof.}

When nothing has been announced in the first period, the announcement game between the challenger and the incumbent is a simultaneous game. Table 1 shows, for the case in which $t_{j}=1$ the challenger's winning probability if he chooses $p_{j}^{C}=1$ or $p_{j}^{C}=-1$, and $j$ is the decisive issue, given the equilibrium assumption that the voter acts according to his signal. To understand how each entry in the table is computed, consider for example the probability of winning when $t_{j}=1$ and both the incumbent and the challenger follow their signal,

$$
\begin{array}{r}
\operatorname{Pr}\left(s_{j}=1 \mid \omega_{j}=1\right) \cdot \operatorname{Pr}\left(\omega_{j}=1 \mid t_{j}=1\right) \cdot \frac{1}{2} \\
+\operatorname{Pr}\left(s_{j}=-1 \mid \omega_{j}=1\right) \cdot \operatorname{Pr}\left(\omega_{j}=1 \mid t_{j}=1\right) \cdot \delta \\
+\operatorname{Pr}\left(s_{j}=1 \mid \omega_{j}=-1\right) \cdot \operatorname{Pr}\left(\omega_{j}=-1 \mid t_{j}=1\right) \cdot \frac{1}{2} \\
+\operatorname{Pr}\left(s_{j}=-1 \mid \omega_{j}=-1\right) \cdot \operatorname{Pr}\left(\omega_{j}=-1 \mid t_{j}=1\right) \cdot(1-\delta)
\end{array}
$$

Notice that when both candidates make the same announcement, each one has a winning probability of $\frac{1}{2}$, while when they make different announcements the candidate who makes the promise equal to the true state of the world wins with probability $\delta$, while the candidate that makes the promise that is different from the true state of the world wins with probability $1-\delta$. This is due to the fact that the precision of the voter's signals is $\delta$.

Notice moreover that we indicate with $\mathbb{E}\left(\gamma_{j}\right)$ the expected precision of the incumbent, where $\mathbb{E}\left(\gamma_{a}\right)>\mathbb{E}\left(\gamma_{b}\right)=\frac{1}{2}$.

It can be easily seen that $p_{j}^{C}=1$ is dominant when $t_{j}=1$. The same reasoning can be replicated for $t_{j}=-1$. Hence, it is a dominant strategy for the challenger to make promises in accordance with his own signal. 


\begin{tabular}{cc|c|c|c|c|}
\multicolumn{2}{c|}{$t_{j}=1$} & \multicolumn{5}{|c|}{ Incumbent } \\
\hline \multirow{2}{*}{ Challenger } & $p_{j}^{C}=1$ & $p_{j}^{I}=1$ & $p_{j}^{I}=-1$ & $p_{j}^{I}=s_{j}$ & $p_{j}^{I}=-s_{j}$ \\
\cline { 2 - 6 } & $\frac{1}{2}$ & $\delta^{2}$ & $\frac{1}{2}+\frac{\mathbb{E}\left(\gamma_{j}\right)}{2}-\frac{\delta}{2}$ & $1-\frac{\mathbb{E}\left(\gamma_{j}\right)}{2}+\mathbb{E}\left(\gamma_{j}\right) \delta$ \\
+ & & $+(1-\delta)^{2}$ & $-\mathbb{E}\left(\gamma_{j}\right) \delta+\delta^{2}$ & $+\delta^{2}-\frac{3}{2} \delta$ \\
\hline & $p_{j}^{C}=-1$ & $2(1-\delta) \delta$ & $\frac{1}{2}$ & $\frac{3}{2} \delta+\frac{\mathbb{E}\left(\gamma_{j}\right)_{j}}{2}$ & $\begin{array}{c}\frac{1}{2}+\frac{\delta}{2}-\frac{\mathbb{E}\left(\gamma_{j}\right)}{2} \\
-\delta^{2}-\mathbb{E}\left(\gamma_{j}\right) \delta\end{array}$ \\
& & & $-\delta^{2}+\mathbb{E}\left(\gamma_{j}\right) \delta$ \\
\hline
\end{tabular}

Table 1: Challenger's expected probability of winning on issue $j$.

The incumbent's probability of winning when $s_{j}=1$ and the voter acts according to his signal, similarly, can be found in Table 2 .

\begin{tabular}{cc|c|c|c|c|}
\multicolumn{2}{c|}{$s_{j}=1$} & \multicolumn{5}{|c|}{ Challenger } \\
& & $p_{j}^{C}=1$ & $p_{j}^{C}=-1$ & $p_{j}^{C}=t_{j}$ & $p_{j}^{C}=-t_{j}$ \\
\hline \multirow{2}{*}{ Incumbent } & $p_{j}^{I}=1$ & $\frac{1}{2}$ & $\gamma_{j} \delta$ & $\frac{1}{2}+\gamma_{j} \delta+\frac{\delta}{2}$ & $1-\frac{\gamma}{2}+\gamma \delta$ \\
& & & $+\left(1-\gamma_{j}\right)(1-\delta)$ & $-\frac{\gamma_{j}}{2}-\delta^{2}$ & $+\delta^{2}-\frac{3}{2} \delta$ \\
\cline { 2 - 6 } & $p_{j}^{I}=-1$ & $\left(1-\gamma_{j}\right) \delta$ & $\frac{1}{2}$ & $\frac{3}{2} \delta+\frac{\gamma_{j}}{2}$ & $\frac{1}{2}-\frac{\delta}{2}+\frac{\gamma}{2}$ \\
& & $+\gamma_{j}(1-\delta)$ & & $-\delta^{2}-\gamma_{j} \delta$ & $+\delta^{2}-\gamma_{j} \delta$ \\
\hline
\end{tabular}

Table 2: Incumbent's expected probability of winning on issue $j$.

It can be easily checked that, given $\delta>\frac{1}{2}, p_{a}=s_{a}$ is a dominant strategy as long as $\gamma_{a}>\frac{1}{2}$. As for issue $b$, every strategy delivers the same probability of winning, given that $\gamma_{b}=\frac{1}{2}$. The incumbent's expected probability of winning on issue $b$ when $s_{b}=1$ is represented in Table 3 .

\begin{tabular}{|c|c|c|c|c|}
\hline \multirow[t]{2}{*}{$s_{b}=1$} & \multicolumn{4}{|c|}{ Challenger } \\
\hline & $p_{j}^{C}=1$ & $p_{j}^{C}=-1$ & $p_{j}^{C}=t_{j}$ & $p_{j}^{C}=-t_{j}$ \\
\hline$p_{j}^{I}=1$ & & $\frac{1}{2}$ & $\frac{1}{4}+\delta-\delta^{2}$ & $\frac{3}{4}-\delta+\delta^{2}$ \\
\hline$p_{j}^{I}=-1$ & & $\frac{1}{2}$ & $\frac{1}{4}+\delta-\delta^{2}$ & $\frac{3}{4}-\delta+\delta^{2}$ \\
\hline
\end{tabular}

Table 3: Incumbent's expected probability of winning on issue $b$.

It remains to be checked that the voter has an incentive to follow his own signal whenever the two policy proposals are in contrast. This is trivially the case when the disagreement is on issue $b$ (as the voter has the same precision of the challenger and a greater precision than the incumbent), and when the disagreement is on issue $a$ and the voter agrees with the incumbent. When the 
disagreement is on $a$ and the voter agrees with the challenger the condition is guaranteed by the assumption $\gamma<\frac{\delta^{2}}{1-2 \delta+2 \delta^{2}}$.

Claim 3 If nothing has been announced in the first period on issue $j$, there is no second period equilibrium in which either $p_{j}^{I}=p_{j}^{C}=1$ or $p_{j}^{I}=p_{j}^{C}=-1$ regardless of the signal.

Proof. In order to show that such a strategy combination is an equilibrium we need to find out-of-equilibrium beliefs that prevent candidates from deviating.

Suppose for example that we consider issue $a$ and the constant strategy profile is $p_{a}^{I}=p_{a}^{C}=1$. Let's consider a possible deviation of the challenger who may want to promise $p_{a}^{C}=-1$ if $t_{a}=-1$. The equilibrium strategy gives the challenger an expected probability of winning equal to $1 / 2$. After the deviation, the voter would observe two different policy proposals. Crucially, the voter's signal has the same precision as the challenger, so that, when in contrast, the voter prefers to follows his own signal as we assumed in the model. This implies that whatever the out-of-equilibrium belief, the voter follows his own signal if the challenger deviates. ${ }^{13}$ The challenger's expected probability of winning after the deviation therefore is: $\delta^{2}+(1-\delta)^{2}>\frac{1}{2}$. Hence, the challenger has an incentive to deviate and the abovementioned strategy profile is not an equilibrium.

The proofs for the other constant strategy and the other issue can be obtained analogously.

Claim 4 If nothing has been announced in the first period on issue $j$, there is no second period equilibrium in which either $p_{j}^{I}=1=-p_{j}^{C}$ or $p_{j}^{I}=-1=-p_{j}^{C}$.

Proof. In such a strategy profile, each candidate specializes on one of the two policy proposals. Consider for example issue $a$ and the case in which the challenger promises $p_{a}^{C}=1$ and the incumbent promises $p_{a}^{I}=-1$. However, the

\footnotetext{
$\overline{{ }^{13} \text { Notice that this would not always }}$ be the case if the incumbent deviates, as his expected precision may be higher than the voter's one.
} 
challenger, for example, has an incentive to deviate to $p_{a}^{C}=-1$ when $t_{a}=-1$. This is due to the fact that the voter randomizes when candidates offer the same policy. Hence, the probability of being elected after deviating is $\frac{1}{2}>1-\delta$ which is the probability of being elected if he sticks to the proposed strategy profile.

The proofs for the other pair of constant strategies and the other issue can be obtained analogously.

Claim 5 If nothing has been announced in the first period on issue $j$, there is no second period equilibrium in which $p_{j}^{I}=-s_{j}$ and/or $p_{j}^{C}=-t_{j}$.

Proof. Such an equilibrium can arise in three ways.

i. One candidate can use a constant strategy and the other one a strategy that is opposite to the signal. If the challenger is the one proposing a policy which is opposite to the signal the voter will vote according to his own signal whenever the policy proposals differ. In this case, however, the challenger has an incentive to reveal his signal truthfully, as this increases his probability of winning. If instead the incumbent proposes a policy which is opposite to his signal, the voter's behavior depends on the relation between $\mathbb{E}\left(\gamma_{i}\right)$ and $\delta$. If $\mathbb{E}\left(\gamma_{i}\right)<\delta$ the reasoning is the same as for the challenger. If instead $\mathbb{E}\left(\gamma_{i}\right)>\delta$ the voter will choose the challenger whenever the policy proposals differ. Hence, the incumbent has an incentive to propose the same constant policy as the challenger, which guarantees him a probability of winning equal to $\frac{1}{2}$.

ii. One candidate can use the truthful strategy, and the other one a strategy that is opposite to the signal. In this case, the winning probability of the candidate who adopts the latter strategy is either $\frac{1}{2}$ or 0 . Such candidate can improve his probability of winning by truthfully revealing his own signal. This deviation increases the frequency with which the two candidates 
propose the same policy, hence it increases the likelihood of having a probability of winning of $\frac{1}{2}$.

iii. Another possibility is that both candidates can propose a policy which is opposite to their signal. In this case, however, the voter chooses according to his own signal whenever the proposals differ. So both candidates can improve their probability of winning by truthfully revealing their signal.

Claim 6 If nothing has been announced in the first period on issue $j$, there is no second period equilibrium in which only one candidate proposes a policy equal to his signal.

Proof. Such an equilibrium can arise in two ways.

i. One candidate proposes a policy that corresponds to his signal, and the other one a policy which is opposite to his signal. We already proved that this cannot be an equilibrium (see Claim 5 part ii).

ii. One candidate proposes a constant policy and the other one a policy which corresponds to the signal. If the candidate that proposes the policy corresponding to the signal is the challenger, the voter votes according to his signal when the policy proposals differ. In this case, the incumbent increases his probability of winning by proposing the policy equal to his signal. The same reasoning applies if the incumbent proposes $p_{b}^{I}=s_{b}$. If instead the incumbent proposes $p_{a}^{I}=s_{a}$, the voter always votes for the incumbent when the policies differ. Hence, the challenger has an incentive to follow his own signal, and increase the probability of proposing the same policy as the incumbent in which case he wins with probability $\frac{1}{2}$. 
Now we consider the incumbent's strategy in the first period. We begin such analysis by noticing that it is never optimal for the challenger to mimic the incumbent's behavior on issue $b$, and nor for the incumbent to promise something on issue $b$, given that his signal on $b$ is uninformative.

Claim 7 The challenger does not mimic any first period announcement on $b$; the incumbent announces $p_{b}^{I}$ in period 1 only if $\zeta=B$.

Proof. First of all notice that the incumbent is completely uninformed on issue b. Therefore, for any value of $s_{b}, \operatorname{Pr}\left[\omega_{b}=-1 \mid s_{b}\right]=\operatorname{Pr}\left[\omega_{b}=1 \mid s_{b}\right]=\frac{1}{2}$.

As a first consequence of this, the challenger never finds profitable to mimic his promise on $b$ in the second period; by mimicking the incumbent's behavior the challenger's probability of winning is $\frac{1}{2}$, while by not mimicking it is $\delta^{2}+(1-\delta)^{2}>$ $\frac{1}{2}$.

Therefore the only effect that the incumbent has on the electoral campaign if he promises $p_{b}^{I}$ in the first period is to increase the perceived relevance of $b$, that is to increase the probability that $b$ is the decisive issue. This implies that his probability of winning by releasing an early statement on $b$ is lower than his probability of winning when he waits the second period to make announcements.

We now consider the challenger's mimicking incentives when the incumbent makes an early announcement on $a$.

Claim 8 Assume that a set $G$ of incumbent's types promise $p_{a}^{I}=s_{a}$ in the first period when $\zeta=\emptyset$, while types which belong to the complement set do not promise 
anything in the first period. In this case the challenger mimics the incumbent's promise iff $\frac{(1-z) F(G) 2 k}{z(2 k-1)+(1-z) F(G) 2 k} \mathbb{E}\left(\gamma_{a} \mid \gamma_{a} \in G\right)+\frac{z(2 k-1)}{z(2 k-1)+(1-z) F(G) 2 k} \mathbb{E}\left(\gamma_{a}\right)>\delta$.

Proof. Let $\mathbb{E}\left(\gamma_{a} \mid A\right)$ be the expected $\gamma_{a}$ conditional to the fact that the incumbent has announced his policy in the first period. Upon observing $p_{a}^{I}$ announced in the first period, the challenger believes that there is an emergency on $a$ with probability $\frac{z(2 k-1)}{z(2 k-1)+(1-z) F(G) 2 k}$, where $F(G)$ is the measure of the set $G$. This comes from the fact that the challenger believes that $a$ is relevant with probability $\frac{2 k-1}{2 k}$, and that there is an emergency on the relevant issue with probability $z$. Therefore

$\mathbb{E}\left(\gamma_{a} \mid A\right)=\frac{(1-z) F(G) 2 k}{z(2 k-1)+(1-z) F(G) 2 k} \mathbb{E}\left(\gamma_{a} \mid \gamma_{a} \in G\right)+\frac{z(2 k-1)}{z(2 k-1)+(1-z) F(G) 2 k} \mathbb{E}\left(\gamma_{a}\right)$

Given that he does not affect which issue the election is decided upon, the challenger chooses his optimal promise on each issue $a$ in order to maximize the probability of winning if $a$ is decisive. This probability is equal to $\frac{1}{2}$ if the challenger mimics the incumbent by setting $p_{a}^{C}=p_{a}^{I}$.

If $t_{a}=p_{a}^{I}$ the challenger trivially sets $p_{a}^{C}=t_{a}=p_{a}^{I}$ and wins with probability $\frac{1}{2}$. If $t_{a} \neq p_{a}^{I}$ and the challenger does not mimic the incumbent, his probability of winning is

$$
\begin{aligned}
& \operatorname{Pr}\left(\omega_{a}=t_{a} \mid t_{a} \neq s_{a}\right) \delta+\operatorname{Pr}\left(\omega_{a}=-t_{a} \mid t_{a} \neq s_{a}\right)(1-\delta) \\
= & \frac{\delta\left(1-\mathbb{E}\left(\gamma_{a} \mid A\right)\right)}{\delta_{a}\left(1-\mathbb{E}\left(\gamma_{a} \mid A\right)\right)+\mathbb{E}\left(\gamma_{a} \mid A\right)(1-\delta)} \delta+\frac{(1-\delta) \mathbb{E}\left(\gamma_{a} \mid A\right)}{\delta_{a}\left(1-\mathbb{E}\left(\gamma_{a} \mid A\right)\right)+\mathbb{E}\left(\gamma_{a} \mid A\right)(1-\delta)}(1-\delta)
\end{aligned}
$$

which is greater than $\frac{1}{2}$ if $\mathbb{E}\left(\gamma_{j} \mid A\right)>\delta$.

We now focus on the incumbent's behavior on issue $a$. First we show that it is optimal for the incumbent to promise $p_{a}^{I}=s_{a}$ also when he makes announcements in the first period. Then we show that the incumbent's strategy is monotone in $\gamma_{a}$; for a given strategy of the challenger, if a type $\bar{\gamma}_{a}$ finds optimal to make an early announcement on $a$, any lower type $\left(\gamma_{a}<\bar{\gamma}_{a}\right)$ finds it optimal too. 
Claim 9 The incumbent promises $p_{a}^{I}=s_{a}$ also in the first period.

Proof. There are two possible cases, depending on the challenger's behavior.

i. If the challenger mimics the incumbent, then the probability of winning on that issue is $\frac{1}{2}$ regardless of what the incumbent promised.

ii. If there is a positive probability that the challenger does not mimic the incumbent, then promising $p_{j}^{I}=s_{j}$ yields a strictly higher payoff, as shown in the simultaneous case.

Claim 10 The incumbent's optimal timing strategy is monotone in his type: if it is optimal for the incumbent to speak on a for some type $\bar{\gamma}_{a}$, then it is optimal for him to speak also for any $\gamma_{a}<\bar{\gamma}_{a}$. Moreover, if the challenger mimics the incumbent with probability 1 , such threshold is given by $\Xi$ defined as the minimum of 1 and the solution to the following implicit equation and the maximum of 0.5 and the solution to the implicit equation

$$
\Xi=\delta+\frac{([2 F(\Xi)-(2 F(\Xi)-1) z]-2 F(\Xi)(1-z))\left(\frac{1}{4}-\delta+\delta^{2}\right)}{(2 k-1)\left(\delta-\frac{1}{2}\right)[2 F(\Xi)-(2 F(\Xi)-1) z]} .
$$

Proof. Assume that the challenger mimics the incumbent if he speaks in the first period, and suppose that in equilibrium it is optimal for the incumbent to speak on $a$ for some type $\bar{\gamma}_{a}$. In this case it is optimal for him to speak also for any $\gamma_{a}<\bar{\gamma}_{a}$. To see this, let $G$ be the set of types of the incumbent that speak on $a$ in equilibrium in the first period, and let $F(G)$ be the probability that the incumbent's type belongs to the set $G$. Assume that $\bar{\gamma}_{a} \in G$. In this case the incumbent finds optimal to speak on $a$ in the first period if

$$
\begin{aligned}
& \frac{k[2 F(G)-(2 F(G)-1) z]-(1-z) F(G)}{k[2 F(G)-(2 F(G)-1) z]} \frac{1}{2} \\
+ & \frac{(1-z) F(G)}{k[2 F(G)-(2 F(G)-1) z]}\left(\frac{1}{4}+\delta-\delta^{2}\right)
\end{aligned}
$$


is greater than

$$
\frac{2 k-1}{2 k}\left(\frac{1}{2}+\gamma_{a} \delta-\frac{\gamma_{a}}{2}+\frac{\delta}{2}-\delta^{2}\right)+\frac{1}{2 k}\left(\frac{1}{4}+\delta-\delta^{2}\right) .
$$

Consider now $\gamma_{a} \notin G$ such that $\gamma_{a}<\bar{\gamma}_{a}$. The first equation does not depend on the choice of type $\gamma_{a}$ : even if type $\gamma_{a}$ chooses to speak in the first period, and by doing so belongs to $G$, this does not affect the probability of $G$ given the continuity of the probability distribution. This said, the difference between the two equations is decreasing in $\gamma_{a}$, therefore if the inequality holds for $\bar{\gamma}_{a}$ it holds also for every $\gamma_{a}<\bar{\gamma}_{a}$. The incumbent's choice is thus characterized by a threshold below which the incumbent will speak on $a$ in the first period.

By equating (6) and (7) we find that the threshold when the challenger mimics the incumbent with probability 1 is $\Xi$ defined as the minimum of 1 and the solution to the implicit equation and the maximum of 0.5 and the solution to the implicit equation

$$
\begin{aligned}
\Xi & =\delta+\frac{([2 F(\Xi)-(2 F(\Xi)-1) z]-2 F(\Xi)(1-z))\left(\frac{1}{4}-\delta+\delta^{2}\right)}{(2 k-1)\left(\delta-\frac{1}{2}\right)[2 F(\Xi)-(2 F(\Xi)-1) z]} \\
& =\delta+\frac{z\left(\delta-\frac{1}{2}\right)^{2}}{(2 k-1)\left(\delta-\frac{1}{2}\right)[2 F(\Xi)-(2 F(\Xi)-1) z]} \\
& =\delta+\frac{z\left(\delta-\frac{1}{2}\right)}{(2 k-1)[2 F(\Xi)-(2 F(\Xi)-1) z]} .
\end{aligned}
$$

The same reasoning can be applied to the case in which the challenger mimics the incumbent only with probability $\beta<1$.

Claims 11, 12 and 13 analyze the equilibrium behavior in the three different parametric regions.

Claim 11 If $\mathbb{E}\left(\gamma_{a}\right)<\delta$ the incumbent announces $p_{a}^{I}$ in the first period and the challenger does not mimic him.

Proof. Let the unconditional expected value of $\gamma_{a}$ be smaller than $\delta$. This implies that the expected precision of the incumbent given that he speaks in 
the first period is never be greater than $\delta$, given that the incumbent adopts a threshold strategy in which he make early announcements for low types (Claim 10). As a consequence, promising $s_{a}$ in the first period is always optimal for the incumbent, since it increases the probability that the voters look at issue $a$ without inducing any loss in terms of probability of winning on issue $a$.

Claim 12 If $\frac{(1-z) F(\Xi) 2 k}{z(2 k-1)+(1-z) F(\Xi) 2 k} \mathbb{E}\left(\gamma_{a} \mid \gamma_{a} \leq \Xi\right)+\frac{z(2 k-1)}{z(2 k-1)+(1-z) F(\Xi) 2 k} \mathbb{E}\left(\gamma_{a}\right)>\delta$ the incumbent announces $p_{a}^{I}$ in the first period if and only if $\gamma_{a}<\Xi$ and the challenger mimics him on a with probability 1.

Proof. We proved in Claim 10 that the incumbent makes an early announcement on issue $a$ for types $\gamma<\Xi$ even if the challenger mimics him with probability 1 . If $\frac{(1-z) F(\Xi) 2 k}{z(2 k-1)+(1-z) F(\Xi) 2 k} \mathbb{E}\left(\gamma_{a} \mid \gamma_{a} \leq \Xi\right)+\frac{z(2 k-1)}{z(2 k-1)+(1-z) F(\Xi) 2 k} \mathbb{E}\left(\gamma_{a}\right)>\delta$, the incumbent's expected precision when he makes an early announcement on issue $a$ (which is weakly larger than the LHS of the inequality) is larger than the challenger's precision. Therefore the challenger mimics the incumbent with probability 1 . Hence $\Xi$ is the threshold of the incumbent's equilibrium strategy.

Claim 13 Let $\frac{(1-z) F(\Xi) 2 k}{z(2 k-1)+(1-z) F(\Xi) 2 k} \mathbb{E}\left(\gamma_{a} \mid \gamma_{a} \leq \Xi\right)+\frac{z(2 k-1)}{z(2 k-1)+(1-z) F(\Xi) 2 k} \mathbb{E}\left(\gamma_{a}\right)<\delta$ and $\mathbb{E}\left(\gamma_{a}\right)>\delta$. The incumbent announces $p_{a}^{I}$ in the first period if and only if $\gamma_{a}<\Xi\left(\beta^{*}\right)$, where $\Xi\left(\beta^{*}\right)>\Xi$ is such that $\frac{(1-z) F\left(\Xi\left(\beta^{*}\right)\right) 2 k}{z(2 k-1)+(1-z) F\left(\Xi\left(\beta^{*}\right)\right) 2 k} \mathbb{E}\left(\gamma_{a} \mid \gamma_{a} \leq\right.$ $\left.\Xi\left(\beta^{*}\right)\right)+\frac{z(2 k-1)}{z(2 k-1)+(1-z) F\left(\Xi\left(\beta^{*}\right)\right) 2 k} \mathbb{E}\left(\gamma_{a}\right)=\delta$. The challenger mimics the incumbent with probability $\beta^{*}$ such that the incumbent is indifferent between speaking in the first and in the second period when $\gamma_{a}=\Xi\left(\beta^{*}\right)$.

Proof. Notice that this is possible only when $\Xi<1$. We analyze the situation by considering the challenger's possible strategies, and the incumbent's best responses to them: 
i. If the challenger never mimics the incumbent when he makes a promise on $a$ in the first period, the incumbent announces $p_{a}^{I}=s_{a}$ in the first period for any value of $\gamma_{a}$. However, it is optimal for the challenger to mimic the incumbent, given that $\mathbb{E}\left(\gamma_{a}\right)>\delta$.

ii. If the challenger always mimics the incumbent when he makes a promise on $a$ in the first period, the incumbent announces $p_{a}^{I}=s_{a}$ in the first period for any $\gamma_{a}<\Xi$. However, the challenger has no incentive to mimic the incumbent, given that the expected precision of the incumbent signal is $\frac{(1-z) F(\Xi) 2 k}{z(2 k-1)+(1-z) F(\Xi) 2 k} \mathbb{E}\left(\gamma_{a} \mid \gamma_{a} \leq \Xi\right)+\frac{z(2 k-1)}{z(2 k-1)+(1-z) F(\Xi) 2 k} \mathbb{E}\left(\gamma_{a}\right)<\delta$

iii. If the challenger mimics the incumbent with probability $0<\beta<1$, the incumbent has an incentive to promise $p_{a}^{I}=s_{a}$ in the first period as long as the incumbent's probability of winning by announcing $p_{a}^{I}=s_{a}$ in the first period is greater than his probability of winning by being silent in the first period. Let $G=[0.5, \Xi(\beta)]$ be the set of types who speak in the first period. The probability of winning by announcing $p_{a}^{I}=s_{a}$ in the first period is, for an incumbent with type $\gamma_{a}$,

$$
\begin{aligned}
& \frac{k[2 F(G)-(2 F(G)-1) z]-(1-z) F(G)}{k[2 F(G)-(2 F(G)-1) z]}\left(\beta \frac{1}{2}+(1-\beta)\left(\frac{1}{2}+\gamma_{a} \delta-\frac{\gamma_{a}}{2}+\frac{\delta}{2}-\delta^{2}\right)\right) \\
+ & \frac{(1-z) F(G)}{k[2 F(G)-(2 F(G)-1) z]}\left(\frac{1}{4}+\delta-\delta^{2}\right),
\end{aligned}
$$

while his probability of winning by being silent in the first period is

$$
\frac{2 k-1}{2 k}\left(\frac{1}{2}+\gamma_{a} \delta-\frac{\gamma_{a}}{2}+\frac{\delta}{2}-\delta^{2}\right)+\frac{1}{2 k}\left(\frac{1}{4}+\delta-\delta^{2}\right) .
$$

We first notice that, if $\gamma_{a} \leq \delta$, it is always optimal for the incumbent to speak in the first period. If $\gamma_{a}>\delta$, instead, it is optimal for the incumbent to announce $s_{a}$ in the first period only for low values of $\beta$, in particular for

$$
\beta<\frac{z\left(\gamma_{a}-\frac{1}{2}\right)}{(2 k[2 F(G)-(2 F(G)-1) z]-2(1-z) F(G))\left(\gamma_{a}-\delta\right)} .
$$


Now we consider the effect of $\gamma_{a}$ on the difference between equations (9) and (10). Such effect is

$$
\left((1-\beta) \frac{k[2 F(G)-(2 F(G)-1) z]-(1-z) F(G)}{k[2 F(G)-(2 F(G)-1) z]}-\frac{2 k-1}{2 k}\right)\left(\delta-\frac{1}{2}\right) .
$$

The effect is negative for

$$
\beta>\frac{z}{2 k[2 F(G)-(2 F(G)-1) z]-2(1-z) F(G)} .
$$

Given that $\frac{z}{2 k[2 F(G)-(2 F(G)-1) z]-2(1-z) F(G)}<\frac{z\left(\gamma_{a}-\frac{1}{2}\right)}{(2 k[2 F(G)-(2 F(G)-1) z]-2(1-z) F(G))\left(\gamma_{a}-\delta\right)}$ the incumbent's behavior can be summarized as follows:

- if $\beta \leq \frac{z\left(\gamma_{a}-\frac{1}{2}\right)}{(2 k[2 F(G)-(2 F(G)-1) z]-2(1-z) F(G))\left(\gamma_{a}-\delta\right)}$ the incumbent always choose to make an early announcement on $a$;

- if $\beta>\frac{z\left(\gamma_{a}-\frac{1}{2}\right)}{(2 k[2 F(G)-(2 F(G)-1) z]-2(1-z) F(G))\left(\gamma_{a}-\delta\right)}$ the incumbent has a threshold strategy such that he releases early announcements for low values of $\gamma_{a}$ and waits for high values.

We have shown above that no equilibrium can exist in which all types of the incumbent speak in the first period. Therefore the equilibrium must arise with $\beta>\frac{z\left(\gamma_{a}-\frac{1}{2}\right)}{(2 k[2 F(G)-(2 F(G)-1) z]-2(1-z) F(G))\left(\gamma_{a}-\delta\right)}$. Keeping in mind that $G=[0.5, \Xi(\beta)]$ we can see that the threshold $\Xi(\beta)$ is the minimum between 1 and the solution to the following implicit equation and the maximum of 0.5 and the solution to the implicit equation, which results from the indifference of the incumbent between speaking and not-speaking in the first period.

$$
\Xi(\beta)=\frac{\delta(2 k[2 F(\Xi(\beta))-(2 F(\Xi(\beta))-1) z]-2(1-z) F(\Xi(\beta)))-\frac{z}{2}}{\beta(2 k[2 F(\Xi(\beta))-(2 F(\Xi(\beta))-1) z]-2(1-z) F(\Xi(\beta)))-z} .
$$

Notice that $\Xi(1)=\Xi$, therefore

$$
\frac{(1-z) F(\Xi(1)) 2 k}{z(2 k-1)+(1-z) F(\Xi(1)) 2 k} \mathbb{E}\left(\gamma_{a} \mid \gamma_{a} \leq \Xi(1)\right)+\frac{z(2 k-1)}{z(2 k-1)+(1-z) F(\Xi(1)) 2 k} \mathbb{E}\left(\gamma_{a}\right)<\delta
$$


Moreover $\Xi\left(\frac{z\left(\gamma_{a}-\frac{1}{2}\right)}{(2 k[2 F(G)-(2 F(G)-1) z]-2(1-z) F(G))\left(\gamma_{a}-\delta\right)}\right)=1$, therefore the conditional expected value is just $\mathbb{E}\left(\gamma_{a}\right)>\delta$. Given these two relations, and given the continuity of $\Xi(\beta)$ (implied by the continuity of the density function) there exists at least one $\beta^{*} \in\left(\frac{z\left(\gamma_{a}-\frac{1}{2}\right)}{(2 k[2 F(G)-(2 F(G)-1) z]-2(1-z) F(G))\left(\gamma_{a}-\delta\right)}, 1\right)$ such that

$$
\frac{(1-z) F\left(\Xi\left(\beta^{*}\right)\right) 2 k}{z(2 k-1)+(1-z) F(\Xi(1)) 2 k} \mathbb{E}\left(\gamma_{a} \mid \gamma_{a} \leq \Xi\left(\beta^{*}\right)\right)+\frac{z(2 k-1)}{z(2 k-1)+(1-z) F\left(\Xi\left(\beta^{*}\right)\right) 2 k} \mathbb{E}\left(\gamma_{a}\right)=\delta
$$

Therefore there is at least one equilibrium in which the incumbent promises $p_{a}^{I}=s_{a}$ in the first period for any $\gamma_{a}<\Xi\left(\beta^{*}\right)$, such that $\frac{(1-z) F\left(\Xi\left(\beta^{*}\right)\right) 2 k}{z(2 k-1)+(1-z) F\left(\Xi\left(\beta^{*}\right)\right) 2 k} \mathbb{E}\left(\gamma_{a} \mid \gamma_{a} \leq\right.$ $\left.\Xi\left(\beta^{*}\right)\right)+\frac{z(2 k-1)}{z(2 k-1)+(1-z) F\left(\Xi\left(\beta^{*}\right)\right) 2 k} \mathbb{E}\left(\gamma_{a}\right)=\delta$, and the challenger mimics him with probability $\beta^{*}$. Moreover all the equilibria in this region have this same structure.

\section{B. Distortions and inefficiencies}

\section{B.1. Benchmark}

The probability of voting such that the correct policy on the relevant issue is implemented in our benchmark case is:

$$
\begin{aligned}
\operatorname{Pr}\left(\omega_{r e l}=p_{r e l}^{*}\right)= & z\left\{\mathbb{E}(r)\left(1-\left(1-\gamma_{a}\right)\left(1-\delta_{a}\right)\right)+\mathbb{E}(1-r)\left(1-\left(1-\gamma_{b}\right)\left(1-\delta_{b}\right)\right)\right\} \\
& +(1-z)\left\{\operatorname { P r } ( r > \frac { 1 } { 2 } ) \left[\mathbb{E}\left(r \mid r>\frac{1}{2}\right)\left(1-\left(1-\gamma_{a}\right)\left(1-\delta_{a}\right)\right)\right.\right. \\
& \left.+\mathbb{E}\left(1-r \mid r>\frac{1}{2}\right)\left(\frac{1+\gamma_{a}-\delta_{a}}{2} \gamma_{b}+\frac{1-\gamma_{a}+\delta_{a}}{2} \delta_{b}\right)\right] \\
& +\operatorname{Pr}\left(r<\frac{1}{2}\right)\left[\mathbb{E}\left((1-r) \mid r<\frac{1}{2}\right)\left(1-\left(1-\gamma_{b}\right)\left(1-\delta_{b}\right)\right)\right. \\
& \left.\left.+\mathbb{E}\left(r \mid r<\frac{1}{2}\right)\left(\frac{1+\gamma_{b}-\delta_{b}}{2} \gamma_{a}+\frac{1-\gamma_{b}+\delta_{b}}{2} \delta_{a}\right)\right]\right\} .
\end{aligned}
$$

In fact, with probability $z$ there is on emergency on the relevant issue and the incumbent is forced to act in the first period. The voters recognize that the issue must be relevant and vote accordingly. With probability $1-z$ the issue is not relevant. In this case the voters' behavior depends on the realization of the public signal $r$. If $r>\frac{1}{2}$, the voters' choice is based on issue $a$; they will 
be able to choose a candidate with the correct proposed policy with probability $1-\left(1-\gamma_{a}\right)\left(1-\delta_{a}\right)$. Therefore, this candidate will be elected that offers the best policy on $a$. With probability $1-r$, however, the relevant issue is $b$. If the incumbent is elected (which happens with probability $\frac{1+\gamma_{a}-\delta_{a}}{2}$ ) the probability of having the correct policy on $b$ is $\gamma_{b}$; if the challenger is elected (with probability $\frac{1-\gamma_{a}+\delta_{a}}{2}$ ) the probability of having a correct policy on $b$ is $\delta_{b}$. If $r<\frac{1}{2}$, the voters base their choice on issue $b$ and the probability of voting for the correct policy is symmetric.

\section{B.2. Analysis of the distortions}

We separately consider the three parametric regions that are relevant for the equilibrium analysis.

$\mathbb{E}\left(\boldsymbol{\gamma}_{\mathbf{a}}\right)<\boldsymbol{\delta}$. In this case the incumbent always speaks early on issue $a$ and the challenger never mimicks him; the expected welfare given $\gamma_{a}$ becomes:

$$
\begin{aligned}
\operatorname{Pr}\left(\omega_{r e l}=p_{r e l}^{*}\right)= & z\left\{\mathbb{E}(1-r)\left(1-\left(1-\gamma_{b}\right)\left(1-\delta_{b}\right)\right)\right\} \\
& +(1-z+z \cdot \mathbb{E}(r))\left\{\operatorname { P r } ( r > \frac { 1 } { 2 } ) \left[\mathbb{E}\left(r \mid r>\frac{1}{2}\right)\left[1-\left(1-\gamma_{a}\right)\left(1-\delta_{a}\right)\right]\right.\right. \\
& \left.+\mathbb{E}\left(1-r \mid r>\frac{1}{2}\right)\left(\frac{1+\gamma_{a}-\delta_{a}}{2} \gamma_{b}+\frac{1-\gamma_{a}+\delta_{a}}{2} \delta_{b}\right)\right] \\
& +\operatorname{Pr}\left(\frac{1-z}{2-z}<r \leq \frac{1}{2}\right)\left[\mathbb{E}\left(r \mid \frac{1-z}{2-z}<r \leq \frac{1}{2}\right)\left[1-\left(1-\gamma_{a}\right)\left(1-\delta_{a}\right)\right]\right. \\
& \left.+\mathbb{E}\left(1-r \mid \frac{1-z}{2-z}<r \leq \frac{1}{2}\right)\left(\frac{1+\gamma_{a}-\delta_{a}}{2} \gamma_{b}+\frac{1-\gamma_{a}+\delta_{a}}{2} \delta_{b}\right)\right] \\
& +\operatorname{Pr}\left(r \leq \frac{1-z}{2-z}\right)\left[\mathbb{E}\left(1-r \mid r \leq \frac{1-z}{2-z}\right)\left[1-\left(1-\gamma_{b}\right)\left(1-\delta_{b}\right)\right]\right. \\
& \left.\left.+\mathbb{E}\left(r \mid r \leq \frac{1-z}{2-z}\right)\left(\frac{1+\gamma_{b}-\delta_{b}}{2} \gamma_{a}+\frac{1-\gamma_{b}+\delta_{b}}{2} \delta_{a}\right)\right]\right\} .
\end{aligned}
$$

The incumbent makes an early statement on issue $a$. This results in two distortions due to the voters inference regarding the relevance of the issue and the presence of an emergency. Since the incumbent only speaks on $a$, emergency is recognized on issue $b$. An emergency on issue $a$, however, cannot be identified. In this case, the voter is harmed since they do not 
gain certainty about the relevant issue, as they do in the benchmark case. Furthermore, the probability that issue $a$ is the relevant one is distorted. For values of $r$ between $\frac{1-z}{2-z}$ and $\frac{1}{2}$ the voters vote on issue $a$, although $b$ is more likely to be the relevant issue.

$$
\frac{(1-\mathbf{z}) \mathbf{F}(\boldsymbol{\Xi}) \mathbf{2 k}}{\mathbf{z}(\mathbf{2 k}-\mathbf{k})+(\mathbf{1}-\mathbf{z}) \mathbf{F}(\boldsymbol{\Xi}) \mathbf{2 k}} \mathbb{E}\left(\gamma_{\mathbf{a}} \mid \gamma_{\mathbf{a}} \leq \boldsymbol{\Xi}\right)+\frac{\mathbf{z}(\mathbf{2 k}-\mathbf{1})}{\mathbf{z}(\mathbf{2 k}-\mathbf{1})+(\mathbf{1}-\mathbf{z}) \mathbf{F}(\boldsymbol{\Xi}) \mathbf{2 k}} \mathbb{E}\left(\gamma_{\mathbf{a}}\right)<\boldsymbol{\delta} \text { and } \mathbb{E}\left(\gamma_{\mathbf{a}}\right)>\boldsymbol{\delta}
$$

Whenever $\mathbb{E}\left(\gamma_{a}\right)>\delta$ the equilibria display the following behavior: the incumbent makes an early annoucement for low types, and speaks in the second period for high types; the challenger mimicks him with positive probability whenever he speaks. The differences are the threshold type that induces the incumbent to change behavior and the probability of mimicking. In this first region the threshold type is $\Xi\left(\beta^{*}\right)$, and the probability of mimicking is $\beta \in[0,1]$. The expected welfare depends on whether $\gamma_{a}>\Xi\left(\beta^{*}\right)$ or not.

- $\gamma_{\mathbf{a}}>\boldsymbol{\Xi}\left(\boldsymbol{\beta}^{*}\right)$. If the incumbent's competence is such that he only speaks when there is an emergency and then gets mimicked by the challenger with probability $\beta$, the probability of electing a candidate who proposes the correct policy on the relevant issue is,

$$
\begin{aligned}
\operatorname{Pr}\left(\omega_{\text {rel }}=p_{r e l}^{*}\right)= & z\left\{\mathbb{E}(r)\left[\beta \gamma_{a}+(1-\beta)\left(1-\left(1-\gamma_{a}\right)\left(1-\delta_{a}\right)\right)\right]+\mathbb{E}(1-r)\left(1-\left(1-\gamma_{b}\right)\left(1-\delta_{b}\right)\right)\right\} \\
& +(1-z)\left\{\operatorname { P r } ( r > \frac { 1 } { 2 } ) \left[\mathbb{E}\left(r \mid r>\frac{1}{2}\right)\left(1-\left(1-\gamma_{a}\right)\left(1-\delta_{a}\right)\right)\right.\right. \\
& \left.+\mathbb{E}\left(1-r \mid r>\frac{1}{2}\right)\left(\frac{1+\gamma_{a}-\delta_{a}}{2} \gamma_{b}+\frac{1-\gamma_{a}+\delta_{a}}{2} \delta_{b}\right)\right] \\
& +\operatorname{Pr}\left(r<\frac{1}{2}\right)\left[\mathbb{E}\left((1-r) \mid r<\frac{1}{2}\right)\left(1-\left(1-\gamma_{b}\right)\left(1-\delta_{b}\right)\right)\right. \\
& \left.\left.+\mathbb{E}\left(r \mid r<\frac{1}{2}\right)\left(\frac{1+\gamma_{b}-\delta_{b}}{2} \gamma_{a}+\frac{1-\gamma_{b}+\delta_{b}}{2} \delta_{a}\right)\right]\right\}
\end{aligned}
$$

where $\beta=\beta^{*}$.

The incumbent only speaks when there is an emergency, similar to the benchmark. If the emergency is on issue is $a$, the high expected 
competence $\mathbb{E}\left(\gamma_{a}\right)$ makes the challenger mimic the incumbent with probability $\beta$, thus reducing the probability that a candidate with the right policy is up for election from $1-\left(1-\gamma_{a}\right)\left(1-\delta_{a}\right)$ to $\beta \gamma_{a}+(1-$ $\beta)\left(1-\left(1-\gamma_{a}\right)\left(1-\delta_{a}\right)\right)$.

- $\gamma_{\mathbf{a}}<\boldsymbol{\Xi}\left(\boldsymbol{\beta}^{*}\right)$. If the challenger speaks early and is mimicked by the challenger with probability $\beta$, the expected welfare becomes

$$
\begin{aligned}
\operatorname{Pr}\left(\omega_{\text {rel }}=p_{r e l}^{*}\right)= & z\left\{\mathbb{E}(1-r)\left(1-\left(1-\gamma_{b}\right)\left(1-\delta_{b}\right)\right)\right\} \\
& +(1-z+z \cdot \mathbb{E}(r))\left\{\operatorname{Pr}\left(r>\frac{1}{2}\right) \beta\left[\mathbb{E}\left(r \mid r>\frac{1}{2}\right)\left[\gamma_{a}\right]+\mathbb{E}\left(1-r \mid r>\frac{1}{2}\right) \frac{\gamma_{b}+\delta_{b}}{2}\right]\right. \\
& +\operatorname{Pr}\left(r>\frac{1}{2}\right)(1-\beta)\left[\mathbb{E}\left(r \mid r>\frac{1}{2}\right)\left[1-\left(1-\gamma_{a}\right)\left(1-\delta_{a}\right)\right]\right. \\
& \left.+\mathbb{E}\left(1-r \mid r>\frac{1}{2}\right)\left(\frac{1+\gamma_{a}-\delta_{a}}{2} \gamma_{b}+\frac{1-\gamma_{a}+\delta_{a}}{2} \delta_{b}\right)\right] \\
& +\operatorname{Pr}\left(\frac{1-z}{2-z}<r \leq \frac{1}{2}\right) \beta\left[\mathbb{E}\left(r \mid \frac{1-z}{2-z}<r \leq \frac{1}{2}\right)\left[\gamma_{a}\right]+\mathbb{E}\left(1-r \mid \frac{1-z}{2-z}<r \leq \frac{1}{2}\right) \frac{\gamma_{b}+\delta_{b}}{2}\right] \\
& +\operatorname{Pr}\left(\frac{1-z}{2-z}<r \leq \frac{1}{2}\right)(1-\beta)\left[\mathbb{E}\left(r \mid \frac{1-z}{2-z}<r \leq \frac{1}{2}\right)\left[1-\left(1-\gamma_{a}\right)\left(1-\delta_{a}\right)\right]\right. \\
& \left.+\mathbb{E}\left(1-r \mid \frac{1-z}{2-z}<r \leq \frac{1}{2}\right)\left(\frac{1+\gamma_{a}-\delta_{a}}{2} \gamma_{b}+\frac{1-\gamma_{a}+\delta_{a}}{2} \delta_{b}\right)\right] \\
& +\operatorname{Pr}\left(r \leq \frac{1-z}{2-z}\right) \beta\left[\mathbb{E}\left(1-r \mid r \leq \frac{1-z}{2-z}\right)\left[1-\left(1-\gamma_{b}\right)\left(1-\delta_{b}\right)\right]+\mathbb{E}\left(r \mid r \leq \frac{1-z}{2-z}\right) \frac{\gamma_{a}+\delta_{a}}{2}\right] \\
& +\operatorname{Pr}\left(r \leq \frac{1-z}{2-z}\right)(1-\beta)\left[\mathbb{E}\left(1-r \mid r \leq \frac{1-z}{2-z}\right)\left[1-\left(1-\gamma_{b}\right)\left(1-\delta_{b}\right)\right]\right. \\
& \left.\left.+\mathbb{E}\left(r \mid r \leq \frac{1-z}{2-z}\right)\left(\frac{1+\gamma_{b}-\delta_{b}}{2} \gamma_{a}+\frac{1-\gamma_{b}+\delta_{b}}{2} \delta_{a}\right)\right]\right\} .
\end{aligned}
$$

$\frac{(\mathbf{1}-\mathbf{z}) \mathbf{F}(\boldsymbol{\Xi}) \mathbf{2 k}}{\mathbf{z}(\mathbf{2} \mathbf{k}-\mathbf{1})+(\mathbf{1}-\mathbf{z}) \mathbf{F}(\boldsymbol{\Xi}) \mathbf{2 k}} \mathbb{E}\left(\gamma_{\mathbf{a}} \mid \boldsymbol{\gamma}_{\mathbf{a}} \leq \boldsymbol{\Xi}\right)+\frac{\mathbf{z}(\mathbf{2 k}-\mathbf{1})}{\mathbf{z}(\mathbf{2} \mathbf{k}-\mathbf{1})+(\mathbf{1}-\mathbf{z}) \mathbf{F}(\boldsymbol{\Xi}) \mathbf{2 k}} \mathbb{E}\left(\gamma_{\mathbf{a}}\right)<\boldsymbol{\delta}$ In this case the incumbent makes an early annoucement for $\gamma_{a}<\Xi$, and speaks in the second period for higher types; the challenger mimicks him whenever he speaks early. The expected welfare depends on $\gamma_{a}$.

- $\gamma_{\mathbf{a}}>\boldsymbol{\Xi}$. If the incumbent's competence is such that he only speaks when there is an emergency and then gets mimicked by the challenger, the probability of electing a candidate who proposes the correct policy on the relevant issue is, 


$$
\begin{aligned}
\operatorname{Pr}\left(\omega_{r e l}=p_{r e l}^{*}\right)= & z\left\{\mathbb{E}(r) \gamma_{a}+\mathbb{E}(1-r)\left(1-\left(1-\gamma_{b}\right)\left(1-\delta_{b}\right)\right)\right\} \\
& +(1-z)\left\{\operatorname { P r } ( r > \frac { 1 } { 2 } ) \left[\mathbb{E}\left(r \mid r>\frac{1}{2}\right)\left(1-\left(1-\gamma_{a}\right)\left(1-\delta_{a}\right)\right)\right.\right. \\
& \left.+\mathbb{E}\left(1-r \mid r>\frac{1}{2}\right)\left(\frac{1+\gamma_{a}-\delta_{a}}{2} \gamma_{b}+\frac{1-\gamma_{a}+\delta_{a}}{2} \delta_{b}\right)\right] \\
& +\operatorname{Pr}\left(r<\frac{1}{2}\right)\left[\mathbb{E}\left((1-r) \mid r<\frac{1}{2}\right)\left(1-\left(1-\gamma_{b}\right)\left(1-\delta_{b}\right)\right)\right. \\
& \left.\left.+\mathbb{E}\left(r \mid r<\frac{1}{2}\right)\left(\frac{1+\gamma_{b}-\delta_{b}}{2} \gamma_{a}+\frac{1-\gamma_{b}+\delta_{b}}{2} \delta_{a}\right)\right]\right\} .
\end{aligned}
$$

The incumbent only speaks when there is an emergency, similar to the benchmark. If the emergency is on issue $a$, the high expected competence $\mathbb{E}\left(\gamma_{a}\right)$ makes the challenger mimic the incumbent, thus reducing the probability that a candidate with the right policy is up for election from $1-\left(1-\gamma_{a}\right)\left(1-\delta_{a}\right)$ to $\gamma_{a}$.

- $\gamma_{\mathrm{a}}<\Xi$

If the challenger speaks early and is mimicked by the challenger, the expected welfare becomes

$$
\begin{aligned}
\operatorname{Pr}\left(\omega_{\text {rel }}=p_{\text {rel }}^{*}\right)= & z\left\{\mathbb{E}(1-r)\left(1-\left(1-\gamma_{b}\right)\left(1-\delta_{b}\right)\right)\right\} \\
& +(1-z+z \cdot \mathbb{E}(r))\left\{\operatorname{Pr}\left(r>\frac{1}{2}\right)\left[\mathbb{E}\left(r \mid r>\frac{1}{2}\right)\left[\gamma_{a}\right]+\mathbb{E}\left(1-r \mid r>\frac{1}{2}\right) \frac{\gamma_{b}+\delta_{b}}{2}\right]\right. \\
& +\operatorname{Pr}\left(\frac{1-z}{2-z}<r \leq \frac{1}{2}\right)\left[\mathbb{E}\left(r \mid \frac{1-z}{2-z}<r \leq \frac{1}{2}\right)\left[\gamma_{a}\right]+\mathbb{E}\left(1-r \mid \frac{1-z}{2-z}<r \leq \frac{1}{2}\right) \frac{\gamma_{b}+\delta_{b}}{2}\right] \\
& \left.+\operatorname{Pr}\left(r \leq \frac{1-z}{2-z}\right)\left[\mathbb{E}\left(1-r \mid r \leq \frac{1-z}{2-z}\right)\left[1-\left(1-\gamma_{b}\right)\left(1-\delta_{b}\right)\right]+\mathbb{E}\left(r \mid r \leq \frac{1-z}{2-z}\right) \frac{\gamma_{a}+\delta_{a}}{2}\right]\right\} .
\end{aligned}
$$

In this case the incumbent makes an early statement and gets mimicked by the challenger. On top of the distortions present in the previous case, the imitation reduces the probability that a candidate who proposes the right policy is available, as in the first range considered. 